\title{
The Journal of Neurology
} and Psychopathology jul 3 - 1934

Vol. XIV.

APRIL, 1934

No. 56

\section{Oríginal Dapers}

\section{GEREBRAL STRUGTURE AND MENTAL FUNCTION AS ILLUSTRATED BY A STUDY OF FOUR DEFEGTIVES' BRAINS}

\author{
By \\ R. J. A. BERRY and R. M. NORMAN \\ Stoke Park Colony
}

As the brain is undoubtedly the physical instrument of those human reactions which collectively form one's ' mind,' it appears reasonable to assume that the more closely the physical instrument can be correlated with its 'psychological ' manifestations the greater will be our appreciation of the diversified causes underlying mental disorders of all kinds, and the greater our chances of arresting or even ' curing' them.

As a result of intensified research, improved technique and more accurate instruments of precision, our knowledge of cortical construction and cytology has within recent years been considerably advanced. But the various studies which have so largely contributed to this more detailed acquaintance with the development and neuronic connections and disconnections of the human cerebral cortex have not, perhaps, always been sufficiently, and in some cases not at all, correlated with the variations of behaviour observed during life. The converse appears to be equally true. In the present instance we propose to attempt this correlation for the brains of four mentally defective patients.

The four brains are those of the following cases :

1. A female imbecile (probably an idiot), age $12 \cdot 1$ years, with a mental age below 3 years.

2. A female imbecile, age $\mathbf{1 2 \cdot 3}$ years, with a Merrill-Palmer mental age of $6 \cdot 1$ years.

3. A male Mongolian imbecile, age $\mathbf{2 3 \cdot 9}$ years. 
4. A feebleminded female, age $20 \cdot 6$ years, with a Binet mental age of 8.6 years, Porteus 8 years, and a combined Binet-Porteus intelligence quotient of 51 .

These four brains have been selected from many others now in our possession, because they cover a representative and diversified series of juvenile and adult defectives. Their macroscopic features have thus been checked from others in the series. But as regards their microscopic examination, it has to be remembered that the histological investigation of any brain is a long and tedious process which demands for its successful elucidation both technical skill and considerable knowledge of brain structure. We therefore consider ourselves fortunate in having had the facilities for examining so completely as many as four. For purposes of comparison, and as a check on our own observations, we have also made use of normal brains, and particularly of the accepted facts of anatomy and embryology and of von Economo's detailed examination of the cytoarchitectonics of normal brains.

Although it is sometimes asserted that these and similar examinations of the brains and associated behaviour of certified mental defectives can throw little or no light on problems of the normal mind and its aberrations, our own experiences do not support such contentions. The legally certified defective only differs in degree - often very minute degree-from those not so certified, and the problems of his neurological ' make-up ' underlie all those of mind and its disorders. We are, therefore, led to hope that investigations such as this may be found of real practical utility to both psychiatrist and psychologist.

\section{IMPORTANGE OF EMBRYOLOGY IN MENTAL SGIENCE}

In the past, anatomical science has dealt faithfully and minutely with the names and descriptions of the sulci and gyri of the neopallial cerebral cortices of both anthropoids and man, but for obvious reasons has but little concerned itself with the origin, growth and development of the underlying causes, namely, the cerebral neurones. It would thus serve no useful purpose to attempt here any elaborate anatomical description of the fissures, sulci and convolutions of these four defective brains. On the other hand, though not perhaps universally recognized, all serious students of mental science would agree that there is an important relationship between the embryological development of the human brain and the subsequent mental reactions and/or aberrations of the adult. As this prenatal development is partly concerned with the formation of the necessary neuroblasts and neurones, which in their turn are responsible for the convoluting and fissuring of the originally smooth or lissencephalic neopallial cerebral hemisphere, the complexity of this fissuring, since it increases the total surface area of the cortex present, is an index of the potentialities of mental development possessed by the individual.

In the earlier months of intrauterine life the grey matter of the cerebral 
cortex is spread out in a relatively thin layer, in which an active histogenesis of spongioblastic (neuroglial) and neuroblastic (neuronic) tissue takes place. Beginning with the fourth month, the pallial wall thickens rapidly, but there is as yet no manifestation of cortical fissuring. But as the cortical cell elements, especially the neurones, now commence to increase in numbers much more rapidly than the smooth pallial wall can provide accommodation for, the latter becomes thrown into folds. These folds become the future convolutions of the brain, and the intervals between them the fissures and sulci. The whole of this process is completed before birth. Even the secondary and tertiary sulci peculiar to the human brain are developments of the last two months of intrauterine life. Embryologically considered, it would appear that the cerebral convolutions and sulci result from cortical cell growth, that mentality depends on such cell growth, and that the foundations of these are laid down before birth. From such a standpoint it appears to be certain that the causes of the primary or endogenous amentias are to be sought in changes well established before birth, and not afterwards.

\section{THE PRE- AND POSTGENTRAL GORTIGAL AREAS}

The three radial sulci - central, precentral, and postcentral-and the two gyri which, developmentally, are responsible for their appearance-namely, the precentral and postcentral-play such an important part in the mentality of every individual that they may be first briefly examined.

The postcentral gyrus forms one of the three most important strongly receptive areas of the cortex, and is largely granulous in construction. The precentral gyrus, on the other hand, is agranulous in structure, 'motor' in function, and corresponds roughly to the ventral grey column of a spinal cord segment, whereas the postcentral gyrus is analogous to the 'sensory' dorsal grey column of a similar segment.

Until about the end of the sixth month of intrauterine life there is nothing to differentiate the above mentioned sulci and gyri from the rest of the smooth neopallial cerebral wall. But as cell growth in the gyri concerned commences about this period to undergo a rapid proliferation, the pallial wall is thrown into folds, between which is developed the central sulcus. The central sulcus (fig. 1, no. 1) is therefore an infolding of cortex between two areas of different structure and function, the precentral and postcentral gyri. The cortical areas in question form the sensorimotor part of Flechsig's ' primary sense zones,' which he has shown have almost completed their development shortly after birth. It is thus obvious that whether the neurones of the receptor postcentral and effector precentral gyri be examined from the standpoint of their cytons (von Economo), or the myelinization of their axons (Flechsig), their main development is completed before, or just after, birth. If their development is not so completed, the future mentality of the individual must be profoundly modified, because it is impossible to 
conceive any deprivation of such an important somæsthetic area as the postcentral gyrus leading to any other condition than a manifestation, in greater or less degree, of ' idiocy from deprivation of the senses.'

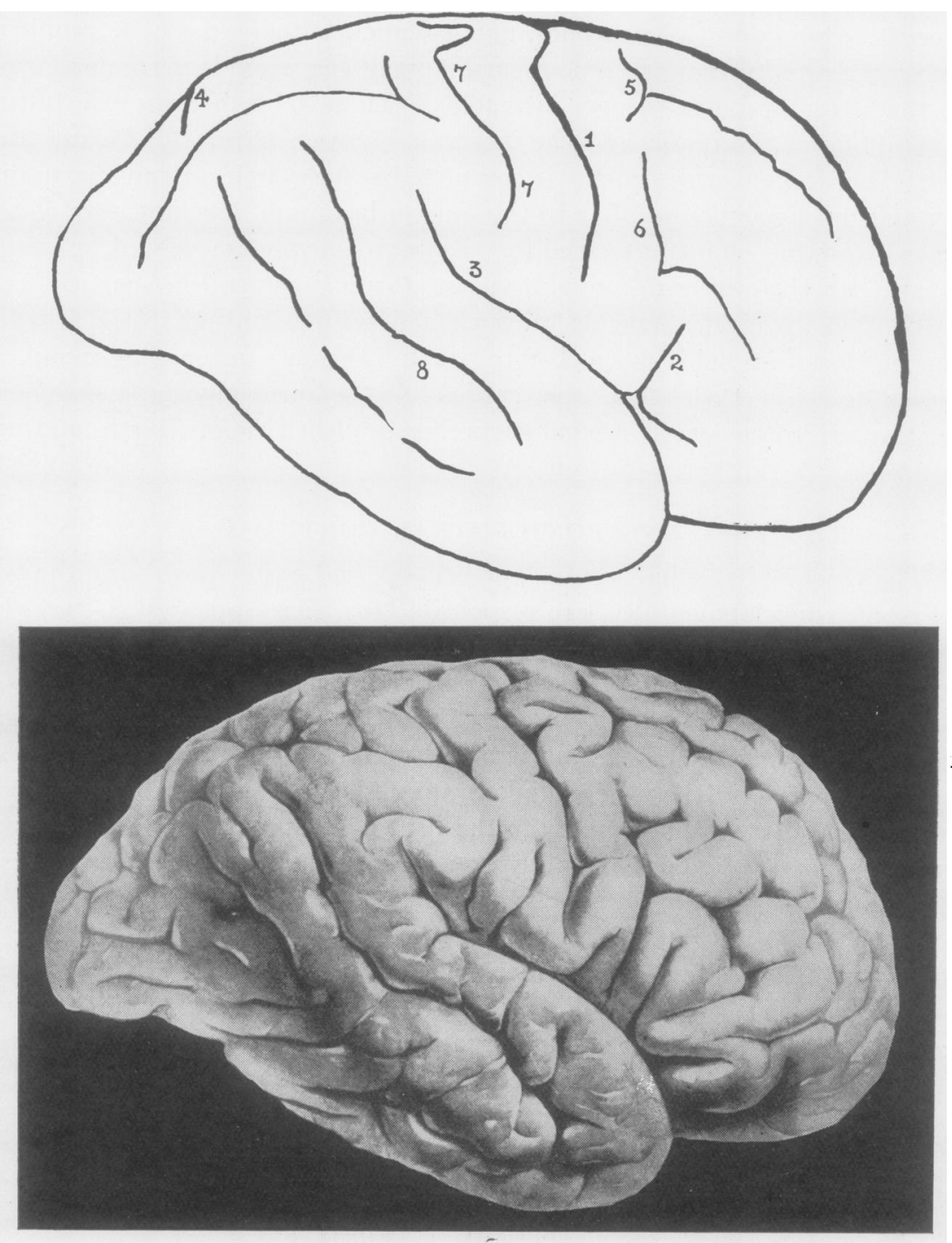

Fig. 1.-A Normal Brain.

Turning now to the four defectives' brains (figs. 2, 3, 4 and 5) with which this paper deals, it can be seen at once that they depart very considerably from those standards of normal development which are essential to the manifestation of a normal mentality (see fig. 1). 
In fig. 2, the brain of a 12-year-old imbecile, the middle section of the postcentral sulcus (no. 7) cuts into the central sulcus (no. 1) and the vitally important receptive postcentral gyrus is so reduced as to be almost invisible on the surface.

In fig. 3 the inferior postcentral sulcus does not appear to have been developed at all, as the posterior limb of the fissure of Sylvius (no. 3) lies next to the central sulcus (no. 1)-an altogether abnormal arrangement.

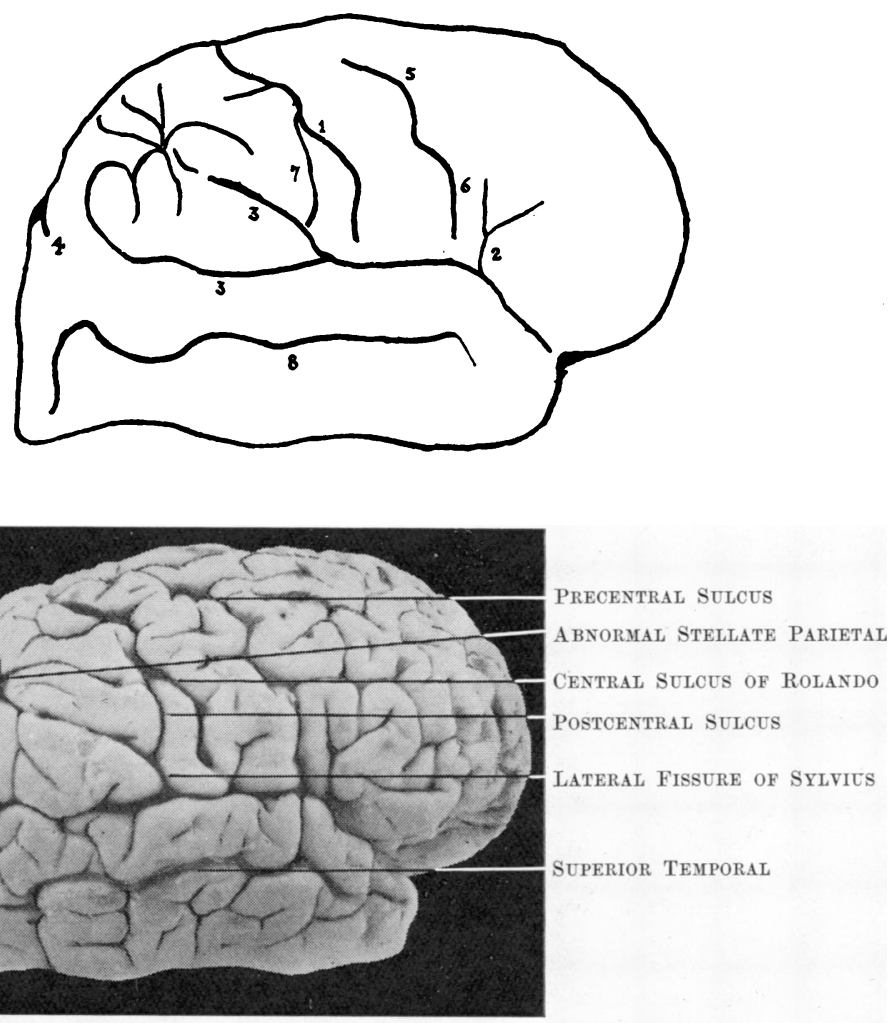

FIG. 2.-Imbecile No. 1.

In fig. 4 the defect appears to have chiefly affected the upper part of the postcentral gyrus and the adjacent parietal lobe, which are both grossly lacking in anything approaching a normal development. The brain of this Mongolian imbecile displays the same general developmental errors as the other brains which belong to patients of no special clinical type.

In fig. 5, which is that of a higher mental grade than the others-namely, a feebleminded woman - the two areas in question, the receptor postcentral and effector precentral gyri, approximate more nearly to normality than do the others. As will be seen later, the chief developmental defects in this brain 
occur in other regions, particularly the frontal operculum and the important parietal association area.

\section{THE EFFECTOR PREGENTRAL GYRUS}

The brains and their photographs show the same general gross departures from normality in the effector precentral gyrus and its limiting sulcus, the
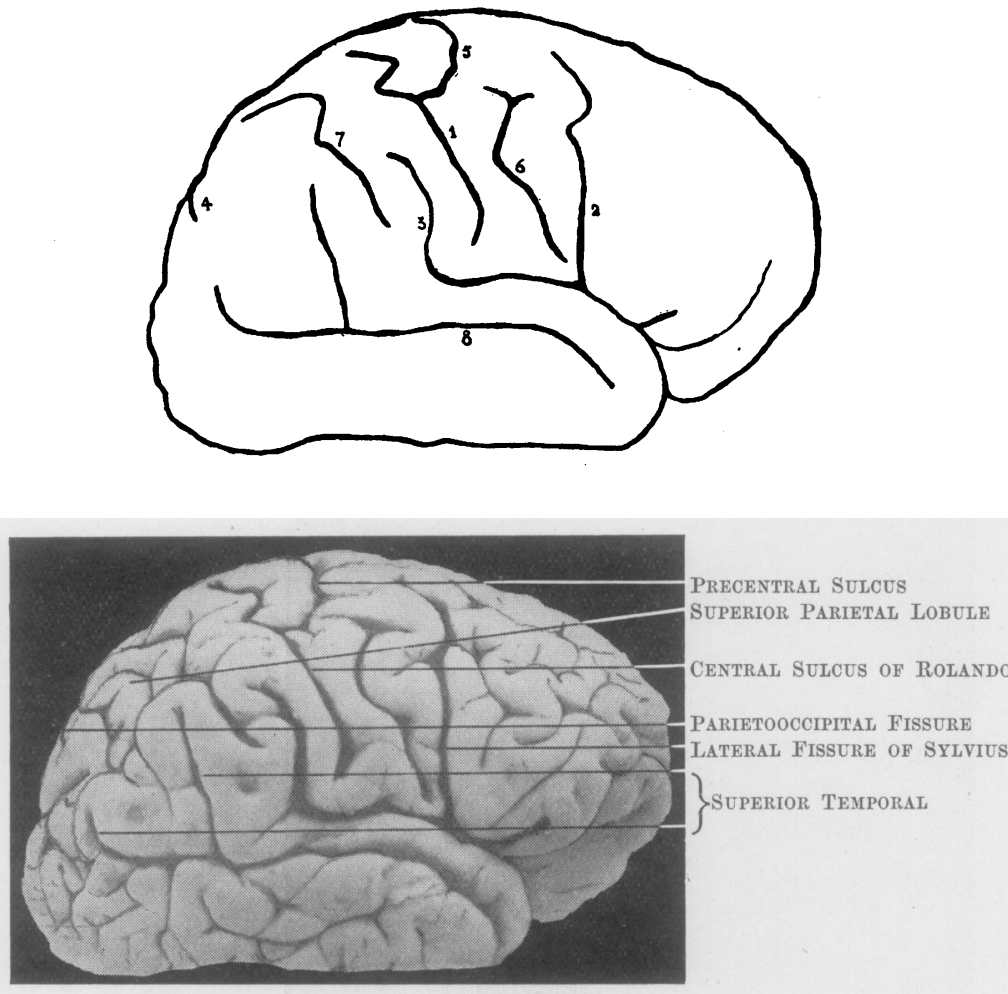

Fig. 3.-Imbecile No. 2.

precentral. In the adult Mongolian imbecile (fig. 4), for example, the inferior precentral sulcus (no. 6) appears not to have been differentiated from the Sylvian fissure (no. 2). In the second of the two imbeciles (fig. 3) the effector precentral gyrus is divided into two parts by a precentral sulcus (no. 5) which passes horizontally across it to cut into the central sulcus (no. 1) -an altogether abnormal arrangement.

In the feebleminded woman (fig. 5) there is a similar, but less complete, subdivision of the precentral gyrus into upper and lower parts, with an altogether abnormal inferior precentral sulcus of $\mathrm{Y}$-shaped form (no. 6). 


\section{THE OPERGULAR GORTIGAL AREAS}

The cortical regions which, in the vicinity of the adult fissure of Sylvius, collectively form the anatomical opercula necessarily affect, by their varying development, the numbers of cortical neurones concerned in the future mentality of the individual. As the principal changes here concerned occur before birth, and not afterwards, they again confirm the view that endogenous
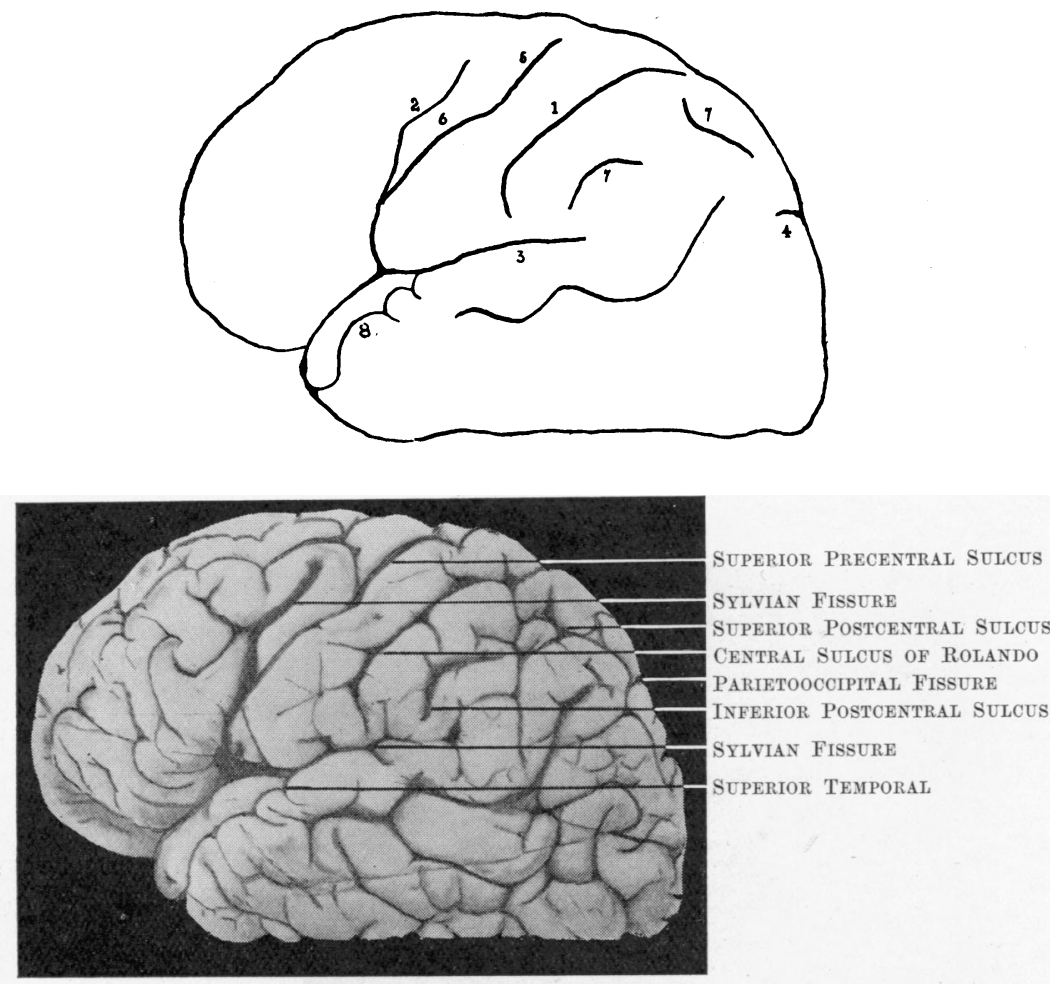

FIG. 4.-Mongolian Imbecile.

amentia is due to embryological errors of development, which are reflected in an imperfect fissuring of the cortex.

The development of the Sylvian fissure commences at the third month of intrauterine life, and is finally completed shortly after birth. Its formation is due to the fact that the neopallial wall in the region of the striate body does not enlarge as rapidly as the parts adjacent to it, thus forming a depression in the cortex known as the Sylvian fossa. As the neighbouring temporal, frontoparietal, and orbital portions become thicker, consequent on the increments in the numbers of their contained neurones, they form inrolling lips or walls, the socalled opercula, which finally cover in the retarded portion of insula. The lines along which the lips meet constitute the fissure of 
Sylvius. The temporal and frontoparietal opercula are formed first, and the frontal and orbital later.

Variations in the form and arrangement of the two anterior limbs of the Sylvian fissure have long been known to, and described by, anatomists, but again such descriptions largely preceded more modern knowledge of the dependence of these variations upon the development and numbers of the underlying cortical neurones. The study of cortical cytology within recent years has, however, demonstrated that variations in the degree of develop-
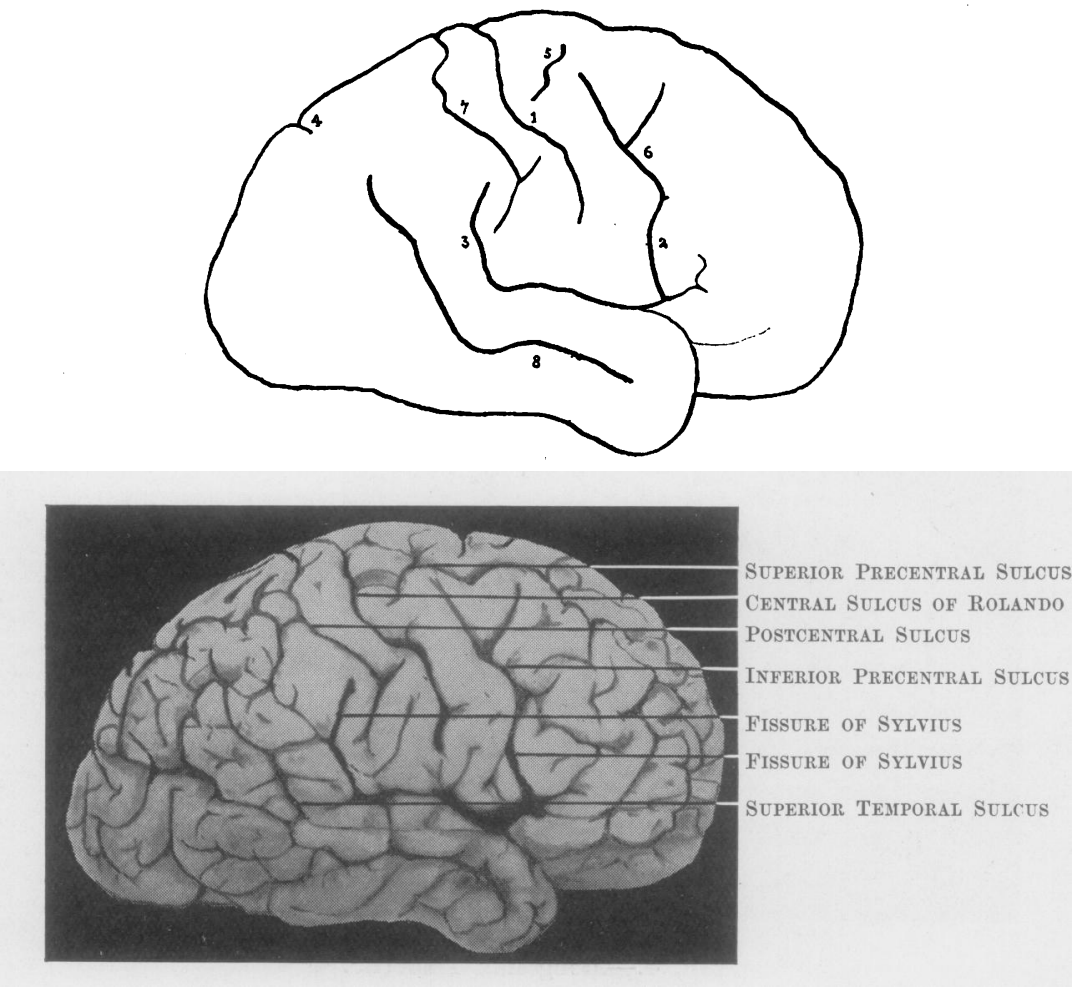

Frg. 5.-Feebleminded.

ment of the frontal operculum determine the shape of the two anterior limbs of the Sylvian fissure between which it lies. When well developed, this operculum separates them from each other so that they assume a $U$ shape ; when the operculum is less well developed the fissures assume a $\mathrm{V}$ shape ; or if the operculum be so poorly developed as not to reach the Sylvian point, then the main limb of the fissure assumes a $Y$ shape. In some forms of still greater arrest of development the anterior portion of the fissure of Sylvius is defective and the insula remains partly exposed. These macroscopic appearances of an undeveloped fissure of Sylvius and the dependent opercula mean the loss, in that brain, of many hundreds of thousands, and more probably 
millions, of neurones with a consequent serious interference with the future mentality of the individual.

In the imbecile's brain which forms fig. 2, the frontal operculum is almost completely absent, and there is a small rudimentary $\mathbf{Y}$-shaped anterior limb of the Sylvian fissure (no. 2).

In the imbecile's brain in fig. 3, the whole of the Sylvian fissure (nos. 2 and 3 ) is so abnormal as to make recognition of the anatomical parts a matter of speculation only. The frontal operculum lies within a U-shaped Sylvian fissure, but one of these limbs appears so unduly prolonged as to bisect the frontal lobe, while the frontoparietal operculum is both small and insufficient.

In the Mongolian imbecile (fig. 4), the insula is exposed and the frontal and frontoparietal opercula are almost nonexistent.

In the feebleminded woman (fig. 5), the frontoparietal operculum is distinctly better developed, but the frontal operculum, which is an offshoot of, in this case, the microgyric frontal association area, is quite abnormal. The anterior limb of the Sylvian fissure (no. 2) also assumes a very odd longstemmed Y-shaped form, consequent apparently on its continuity with the inferior precentral sulcus (no. 6).

It is frankly impossible to study the opercular development of these defectives' brains without realizing that they connote a serious prenatal shortage of cortical neurones, and that such neuronic shortage must have exercised a profound influence in reducing the subsequent mentality to that of the legally recognized mental defective. Nor are these four brains singular in these respects, for the whole of a series of more than $\mathbf{3 0}$ defectives' brains * now in our possession confirms the deductions herein made.

\section{THE PARIETAL ASSOGIATION AREA}

The important area-largely an associational one-known anatomically as the parietal lobe, reveals, in these brains, the same tendency to gross underdevelopment. The accompanying illustrations do not, on account of the convexity of surface concerned, reveal these macroscopic defects quite as clearly as do those already described, but the brains themselves leave no doubt as to the presence of the deficiencies now to be briefly mentioned.

In fig. 1, a normal brain, the usual appearances of the lateral surface of the parietal lobe are shown. The linear extent from the upper end of the central sulcus (no. 1) to the external limb of the parietooccipital fissure (no. 4) is of normal sufficiency, and indicates a parietal associational area adequate for a normal mentality. The other anatomical features, such as the subdivision into superior and inferior parietal lobules, and the further subdivision of the latter, by the upturned ends of the Sylvian (no. 3) and first (no. 8) and second temporal sulci, are seen to be normal and adequate for functional purposes.

But the four defective brains reveal a very different picture. The imbecile's brain in fig. 2 shows a parietal lobe which bears no resemblance to 
any known normal arrangement. It consists only of a few convolutions arranged in a stellate form, from which it is difficult to understand how there can have been a normal mental functioning.

In fig. 3, another imbecile's brain, the convolutions in both the imperfectly developed superior and inferior parietal lobules are so primitive as to consist only of a few gyri so irregular as to make their naked-eye recognition a matter of speculation.

In the Mongolian brain represented in fig. 4, the superior parietal lobule is reduced to a thin bar of cortical tissue. The fissuring of the inferior parietal lobule is also irregular. The superior temporal sulcus (no. 8) is abnormal. Part of it appears to terminate in the anterior part of the Sylvian fissure (no. 3), so that it is doubtful if an angular gyrus is represented.

In fig. 5, that of a feebleminded adult woman, the inferior parietal lobule is relatively well developed, but the superior parietal lobule is little better than in the Mongol.

The importance of these obvious macroscopic manifestations of parietal underdevelopment consists in the fact that this area is largely associational in structure and function, and is set between the three important cortical primary receptive areas for general sensibility, vision, and hearing. The neuronic impulses set up by the stimuli acting upon these important combinations of ' senses' are, or should be, synthetized, amongst other places, within the numerous associational neurones of the parietal lobe. Serious histogenetic errors within this area must, therefore, result in gross irregularities of the sulci and gyri concerned.

The foregoing description has applied only to three of the more important areas of the lateral surface of one cerebral hemisphere, but all show a similar tendency to prenatal lack of development, so serious as to be incompatible with a normal mentality.

\section{OTHER EVIDENGES OF MAGROSGOPIC CORTIGAL MALDEVELOPMENT}

Further evidence of this underdevelopment may be gauged from the following measurements :

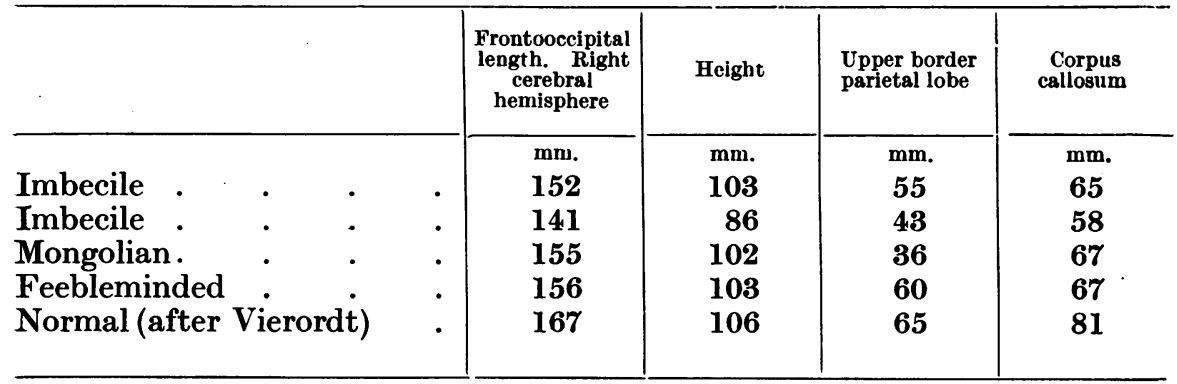


The comparative figures for the corpus callosum alone furnish further evidence of the underdevelopment of these four defective brains, because the corpus callosum is a commissural bundle composed of axons having their cell bodies within the cortical grey matter of the two hemispheres and linking the latter together. If these cells are grossly reduced in numbers the corpus callosum should similarly be reduced in length and other dimensions.

\section{CONGLUSIONS FROM THE MAGROSGOPIC EVIDENGE}

From this macroscopic examination it may be concluded that :

1. These brains are not, and never have been, sufficiently developed to give normal human reactions to normal human environments.

2. The errors responsible for this cerebral insufficiency occurred before birth, and, in these cases, were not due to disease.

\section{MICROSGOPIC EXAMINATION}

Sections were prepared and studied from eight representative areas, in all of which normal cortical structure is known, and a list of which is appended. In each of these eight areas an examination was made of the depth of the various layers and the number of cells per unit present in those layers. These measurements apply to the crowns of the gyri only. The left cerebral hemisphere was examined in Cases 1, 2 and 4; the right hemisphere in Case 3.

1. Frontal Lobe.

(a) Precentral area (von Economo's area F.A.). Sections were taken from the upper part of the gyrus, near the border of the hemisphere.

(b) Agranular frontal area (area F.B.). Sections were taken from the posterior end of the superior frontal gyrus.

(c) Frontal association area (area F.D.). The anterior third of the superior frontal gyrus was examined.

2. Parietal Lobe.

Superior parietal lobule (area P.E.).

3. Temporal Lobe.

(a) The crown of the external surface of the superior temporal gyrus at its middle third (area T.A.).

(b) Parasensory acoustic area (area T.B.). Sections were taken from Heschl's gyrus no. 1.

4. Occipital Lobe.

(a) The visuopsychic area (area O.A.). Sections were taken from the convexity of the hemisphere at the anterior and upper part of the lobe.

(b) The striate or visuosensory area (area O.C.). 


\section{THE RESULTS OBTAINED FROM LAYER MEASUREMENT AND CELL COUNTS}

The depths of the cortical layers at the crowns of the gyri selected are shown in Tables A, and the number of cells per Hammarberg unit in these layers in Tables B.

TABLES A *

Thickness of Cerebral Cortex in Millimetres

1. Precentral Area (Area F.A.)

\begin{tabular}{|c|c|c|c|c|c|c|}
\hline & & Imbecile I & Imbecile II & Mongol & $\begin{array}{l}\text { Feeble- } \\
\text { minded }\end{array}$ & Normal \\
\hline L I . & . & $0 \cdot 29$ & $0 \cdot 25$ & $0 \cdot 21$ & $0 \cdot 29$ & $0 \cdot 18$ \\
\hline L III & . & $1 \cdot 08$ & $0 \cdot 72$ & $1 \cdot 19$ & $1 \cdot 02$ & $1 \cdot 5$ \\
\hline $\mathbf{L ~ V}$ & . & $0 \cdot 68$ & 0.97 & 0.51 & $0 \cdot 81$ & $0.8-0.9$ \\
\hline L VI & . & $1 \cdot 23$ & $1 \cdot 36$ & $1 \cdot 02$ & 0.98 & $1 \cdot 0-1 \cdot 5$ \\
\hline Total & . & $\mathbf{3} \cdot 28$ & $\mathbf{3} \cdot \mathbf{3 0}$ & $2 \cdot 93$ & $3 \cdot 10$ & $4 \cdot 5$ \\
\hline
\end{tabular}

2. Agranular Frontal Area (Area F.B.)

\begin{tabular}{|c|c|c|c|c|c|c|}
\hline & & Imbecile I & Imbecile II & Mongol & $\begin{array}{l}\text { Feeble- } \\
\text { minded }\end{array}$ & Normal \\
\hline $\mathbf{L} \mathbf{I}$ & . & $0 \cdot 34$ & $0 \cdot 34$ & $0 \cdot 25$ & $0 \cdot 32$ & $0 \cdot 22$ \\
\hline L III & . & $1 \cdot 27$ & $1 \cdot 10$ & $1 \cdot 02$ & $1 \cdot 10$ & $1.5+$ \\
\hline $\mathbf{L} \mathbf{V}$. & . & 0.51 & 0.55 & 0.53 & 0.59 & 0.50 \\
\hline L VI & . & $0 \cdot 85$ & $1 \cdot 40$ & $1 \cdot 49$ & $1 \cdot 27$ & $1 \cdot 25-1 \cdot 50$ \\
\hline Total & . & $2 \cdot 97$ & 3.39 & $\mathbf{3} \cdot 29$ & $\mathbf{3} \cdot \mathbf{2 8}$ & $4 \cdot 0$ \\
\hline
\end{tabular}

* In these tables the normal figures are from von Economo and Koskinas' Die Cytoarchitektonik der Hirnrinde des erwachsenen Menschen, 1925, and the smaller English edition The Cytoarchitectonics of the Human Cerebral Cortex, 1929. 
3. Frontal Association Area (Area F.D.)

\begin{tabular}{|c|c|c|c|c|c|c|}
\hline & & Imbecile I & Inbecile II & Mongol & $\begin{array}{l}\text { Feeble- } \\
\text { minded }\end{array}$ & Normal \\
\hline $\mathbf{L} \mathbf{I}$. & . & $0 \cdot 27$ & $0 \cdot 29$ & $0 \cdot 24$ & $0 \cdot 24$ & $0 \cdot 20$ \\
\hline L II & . & $0 \cdot 21$ & $0 \cdot 13$ & $0 \cdot 15$ & $0 \cdot 17$ & $0 \cdot 18$ \\
\hline L III & . & 0.74 & $0 \cdot 68$ & 0.76 & $0 \cdot 84$ & $0 \cdot 80$ \\
\hline L IV & . & $0 \cdot 21$ & $0 \cdot 17$ & $0 \cdot 21$ & $0 \cdot 19$ & $0 \cdot 21$ \\
\hline $\mathbf{L ~ V}$. & . & $0 \cdot 48$ & 0.51 & $0 \cdot 46$ & $0 \cdot 43$ & $0 \cdot 45$ \\
\hline L VI & . & 0.93 & $1 \cdot 19$ & 0.98 & $1 \cdot 01$ & 0.90 \\
\hline Total & . & $2 \cdot 84$ & $2 \cdot 97$ & $2 \cdot 80$ & $\mathbf{2} \cdot 88$ & $2 \cdot 8$ \\
\hline
\end{tabular}

4. Superior Parietal Lobule (Area P.E.)

\begin{tabular}{|c|c|c|c|c|c|c|}
\hline & & Imbecile I & Imbecile II & Mongol & $\begin{array}{l}\text { Feeble- } \\
\text { minded }\end{array}$ & Normal \\
\hline L I . & . & $0 \cdot 27$ & $0 \cdot 25$ & $0 \cdot 25$ & $0 \cdot 21$ & $0 \cdot 18$ \\
\hline L II & . & $0 \cdot 17$ & $0 \cdot 13$ & $0 \cdot 17$ & $0 \cdot 19$ & $0 \cdot 20$ \\
\hline L III & . & $0 \cdot 93$ & 0.93 & $1 \cdot 06$ & $0 \cdot 77$ & $0 \cdot 70$ \\
\hline L IV & . & $0 \cdot 27$ & $0 \cdot 25$ & $0 \cdot 21$ & $0 \cdot 24$ & $0 \cdot 40$ \\
\hline $\mathbf{L ~ V}$ & . & 0.59 & $0 \cdot 38$ & $0 \cdot 34$ & $0 \cdot 48$ & $0 \cdot 40$ \\
\hline L VI & . & $0 \cdot 98$ & $0 \cdot 81$ & $1 \cdot 19$ & 0.72 & 0.90 \\
\hline Total & . & $3 \cdot 22$ & $2 \cdot 75$ & $3 \cdot 22$ & $2 \cdot 61$ & $2 \cdot 6-3 \cdot 0$ \\
\hline
\end{tabular}


5. Superior Temporal Gyrus (Area T.A.)

\begin{tabular}{|c|c|c|c|c|c|c|}
\hline & & Imbecile I & Imbecile II & Mongol & $\begin{array}{l}\text { Feeble- } \\
\text { minded }\end{array}$ & Normal \\
\hline L I . & - & $0 \cdot 27$ & 0.25 & $0 \cdot 29$ & $0 \cdot 27$ & $0 \cdot 22$ \\
\hline L II & • & $0 \cdot 13$ & 0.08 & $0 \cdot 11$ & $0 \cdot 13$ & $0 \cdot 1$ \\
\hline L III & - & $0 \cdot 81$ & $0 \cdot 68$ & $1 \cdot 02$ & $0 \cdot 85$ & 0.95 \\
\hline L IV & & $0 \cdot 19$ & $0 \cdot 17$ & 0.25 & $0 \cdot 21$ & $0 \cdot 18$ \\
\hline L V & & $0 \cdot 42$ & 0.55 & 0.51 & 0.51 & 0.50 \\
\hline L VI & . & 0.93 & $1 \cdot 02$ & $1 \cdot 06$ & 0.93 & $0 \cdot 90$ \\
\hline Total & • & $2 \cdot 75$ & $2 \cdot 75$ & $3 \cdot 24$ & 2.90 & $3 \cdot 0$ \\
\hline
\end{tabular}

6. Parasensory Acoustic Area (Area T.B.)

\begin{tabular}{|c|c|c|c|c|c|c|}
\hline & & Imbecile I & Imbecile II & Mongol & $\begin{array}{l}\text { Feeble- } \\
\text { minded }\end{array}$ & Normal \\
\hline L I . & . & $0 \cdot 27$ & $0 \cdot 25$ & $0 \cdot 29$ & $0 \cdot 25$ & $0 \cdot 23$ \\
\hline L II & . & $0 \cdot 17$ & $0 \cdot 13$ & $0 \cdot 08$ & $0 \cdot 11$ & $0 \cdot 20$ \\
\hline L III & . & $0 \cdot 76$ & $0 \cdot 72$ & 0.98 & $0 \cdot 76$ & 0.90 \\
\hline L IV & . & $0 \cdot 25$ & 0.21 & $\mathbf{0} \cdot 34$ & $0 \cdot 21$ & $0 \cdot 35$ \\
\hline $\mathbf{L} \mathbf{V}$ & . & 0.51 & 0.42 & $0 \cdot 47$ & $0 \cdot 42$ & $0 \cdot 40$ \\
\hline L VI & . & $0 \cdot 85$ & $1 \cdot 02$ & $1 \cdot 06$ & $0 \cdot 81$ & 0.80 \\
\hline Total & . & $2 \cdot 81$ & $2 \cdot 75$ & $3 \cdot 22$ & $2 \cdot 56$ & $3 \cdot 0$ \\
\hline
\end{tabular}


7. Visuopsychic Area (Area O.A.)

\begin{tabular}{|c|c|c|c|c|c|c|}
\hline & & Imbecile I & Imbecile II & Mongol & $\begin{array}{l}\text { Feeble- } \\
\text { minded }\end{array}$ & Normal \\
\hline $\mathbf{L} \mathbf{I}$ & & $0 \cdot 21$ & $0 \cdot 26$ & $0 \cdot 22$ & $0 \cdot 19$ & $0 \cdot 18$ \\
\hline L II & & $0 \cdot 17$ & $0 \cdot 15$ & $0 \cdot 25$ & $0 \cdot 13$ & $0 \cdot 23$ \\
\hline L III & & 0.51 & $0 \cdot 72$ & $0 \cdot 76$ & $0 \cdot 58$ & $0 \cdot 60$ \\
\hline L IV & & $0 \cdot 21$ & $0 \cdot 19$ & $0 \cdot 21$ & $0 \cdot 24$ & $0 \cdot 20$ \\
\hline $\mathbf{L}$. & & $0 \cdot 42$ & $0 \cdot 29$ & $\mathbf{0} \cdot \mathbf{3 0}$ & $0 \cdot 38$ & $0 \cdot 35$ \\
\hline L VI & • & $0 \cdot 73$ & $0 \cdot 68$ & $0 \cdot 64$ & 0.53 & $0 \cdot 70$ \\
\hline Total & & $2 \cdot 25$ & $2 \cdot 29$ & $\mathbf{2 \cdot 3 8}$ & $2 \cdot 05$ & $2 \cdot 3-2 \cdot 6$ \\
\hline
\end{tabular}

8. Visuosensory Area (Area O.C.)

\begin{tabular}{|c|c|c|c|c|c|c|}
\hline & & Imbecile I & Imbecile II & Mongol & $\begin{array}{l}\text { Feeble- } \\
\text { minded }\end{array}$ & Normal \\
\hline L I . & . & $0 \cdot 21$ & $0 \cdot 19$ & $0 \cdot 23$ & $0 \cdot 21$ & $0 \cdot 19$ \\
\hline L II & . & $0 \cdot 06$ & 0.08 & 0.05 & $0 \cdot 04$ & $0 \cdot 12$ \\
\hline L III & . & $0 \cdot 29$ & $0 \cdot 21$ & $0 \cdot 28$ & $0 \cdot 29$ & $0 \cdot 27$ \\
\hline \multirow{3}{*}{ L IV } & $a$ & $0 \cdot 21$ & $0 \cdot 17$ & $\mathbf{0 . 2 1}$ & \multirow[b]{2}{*}{0.61} & \multirow[b]{2}{*}{$0 \cdot 80+$} \\
\hline & $b$ & $0.29\} 0.67$ & $0.29-0.68$ & $0.25\} 0.69$ & & \\
\hline & $c$ & $0 \cdot 17)$ & $0 \cdot 22$ & $0 \cdot 23$ & $0 \cdot 27$ & $0 \cdot 17)$ \\
\hline $\mathbf{L ~ V}$ & 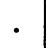 & $0 \cdot 21$ & $0 \cdot 25$ & $0 \cdot 25$ & $0 \cdot 25$ & $0 \cdot 27$ \\
\hline \multirow{2}{*}{ L VI } & $a$ & $0 \cdot 21$ & $0 \cdot 17$ & $0 \cdot 21$ & $0 \cdot 21$ & $0 \cdot 25$ \\
\hline & $b$ & $0 \cdot 38$ & $0 \cdot 29$ & $0 \cdot 38$ & $0 \cdot 42$ & $0 \cdot 20$ \\
\hline Total & . & $2 \cdot 03$ & $1 \cdot 87$ & $2 \cdot 09$ & $2 \cdot 03$ & $2 \cdot 0-2 \cdot 5$ \\
\hline
\end{tabular}


TABLES B

Cell Counts per Hammarberg Unit

1. Precentral Area (Area F.A.)

\begin{tabular}{|c|c|c|c|c|c|c|}
\hline & & Imbecile I & Imbecile II & Mongol & $\begin{array}{l}\text { Feeble- } \\
\text { minded }\end{array}$ & Normal \\
\hline \multirow{4}{*}{ L III } & $a$ & 13 & 21 & 27 & 22 & 30 \\
\hline & $b$ & 16 & 17 & 19 & 15 & 29 \\
\hline & $c$ & 12 & 7 & 12 & 12 & $15+$ \\
\hline & iv & 16 & 16 & & 13 & $12-15$ \\
\hline \multicolumn{2}{|l|}{$\mathbf{L} \mathbf{V}$} & 13 & 16 & 18 & 14 & 16 \\
\hline \multirow{2}{*}{ L VI } & $a$ & 15 & 18 & 24 & 19 & 25 \\
\hline & $b$ & 13 & 14 & 16 & 14 & 15 \\
\hline
\end{tabular}

2. Agranular Frontal Area (Area F.B.)

\begin{tabular}{|c|c|c|c|c|c|c|}
\hline & & Imbecile I & Imbecile II & Mongol & $\begin{array}{l}\text { Feeble- } \\
\text { minded }\end{array}$ & Normal \\
\hline \multirow{4}{*}{ L III } & ii & 21 & 39 & 56 & 53 & 65 \\
\hline & $a$ & 19 & 12 & 27 & 21 & 30 \\
\hline & $b$ & 10 & 11 & 15 & 14 & 25 \\
\hline & $c$ & 11 & 7 & 9 & 13 & 18 \\
\hline $\mathbf{L V}$ & - & 13 & 21 & 18 & 15 & 25 \\
\hline \multirow{2}{*}{ L VI } & & 19 & 22 & 24 & 23 & 24 \\
\hline & & 16 & 13 & 15 & 17 & 15 \\
\hline
\end{tabular}


3. Frontal Association Area (Area F.D.)

\begin{tabular}{|c|c|c|c|c|c|c|}
\hline & & Imbecile I & Imbecile II & Mongol & $\begin{array}{l}\text { Feeble- } \\
\text { minded }\end{array}$ & Normal \\
\hline L II & . & 48 & 47 & 72 & 62 & 75 \\
\hline \multirow{2}{*}{ L III } & $a$ & 12 & 16 & 21 & 21 & 32 \\
\hline & $b$ & 10 & 14 & 20 & 14 & 16 \\
\hline L IV & . & 47 & 44 & 58 & 59 & 85 \\
\hline \multirow{2}{*}{$\mathbf{L ~ V}$} & $a$ & 25 & 25 & \multirow{2}{*}{25} & 26 & 30 \\
\hline & $b$ & 11 & 13 & & 14 & 15 \\
\hline \multirow{2}{*}{ L VI } & & 27 & 24 & 27 & 27 & 30-35 \\
\hline & & 16 & 12 & 15 & 14 & $15-17$ \\
\hline
\end{tabular}

4. Superior Parietal Lobule (Area P.E.)

\begin{tabular}{|c|c|c|c|c|c|c|}
\hline & & Imbecile I & Imbecile II & Mongol & $\begin{array}{l}\text { Feeble- } \\
\text { minded }\end{array}$ & Normal \\
\hline L II & - & 83 & 64 & 67 & 76 & 110 \\
\hline \multirow{3}{*}{ L III } & $a$ & 21 & 30 & 22 & 27 & 50 \\
\hline & $b$ & 15 & 19 & 16 & 16 & 25 \\
\hline & $c$ & 15 & 18 & 14 & 19 & 25 \\
\hline \multirow{2}{*}{ L IV } & $a$ & 41 & 65 & 56 & 54 & 65 \\
\hline & $b$ & 50 & 71 & 52 & 56 & 80 \\
\hline \multirow{2}{*}{$\mathbf{L ~ V}$} & $a$ & 18 & 20 & 22 & 24 & 35 \\
\hline & $b$ & 14 & 18 & 16 & 16 & 17 \\
\hline \multirow{2}{*}{ L VI } & $a$ & 27 & 27 & 24 & 34 & 21 \\
\hline & $b$ & 14 & 18 & 13 & 15 & 10 \\
\hline
\end{tabular}


5. Superior Temporal Gyrus (Area T.A.)

\begin{tabular}{|c|c|c|c|c|c|c|}
\hline & & Imbecile I & Imbecile II & Mongol & $\begin{array}{l}\text { Feeble- } \\
\text { minded }\end{array}$ & Normal \\
\hline L II & • & 75 & 60 & 61 & 70 & 85 \\
\hline L III & - & 18 & 15 & 14 & 17 & 40 \\
\hline L IV & . & 66 & 50 & 39 & 61 & 100 \\
\hline $\mathbf{L ~ V}$ & . & 32 & 26 & 18 & 22 & 40 \\
\hline \multirow{2}{*}{ L VI } & $a$ & 27 & 27 & 21 & 26 & 30 \\
\hline & $b$ & 18 & 13 & 14 & 17 & 15 \\
\hline
\end{tabular}

6. Parasensory Acoustic Area (Area T.B.)

\begin{tabular}{|c|c|c|c|c|c|c|}
\hline & & Imbecile I & Imbecile II & Mongol & $\begin{array}{l}\text { Feeble- } \\
\text { minded }\end{array}$ & Normal \\
\hline \multirow[t]{2}{*}{ L II } & . & 73 & 73 & 70 & 94 & 80 \\
\hline & $a$ & 24 & 31 & 21 & 36 & 44 \\
\hline \multirow[t]{2}{*}{ L III } & $b$ & 16 & 18 & 17 & 32 & 30 \\
\hline & $c$ & 19 & 19 & 17 & 29 & 30 \\
\hline L IV & - & 60 & 67 & 57 & 115 & 125 \\
\hline $\mathbf{L} \mathbf{V}$ & - & 28 & 38 & 33 & 38 & 50 \\
\hline \multirow{2}{*}{$\mathbf{L} \mathbf{V I}$} & $a$ & 30 & 34 & 29 & 42 & 40 \\
\hline & $b$ & 20 & 19 & 17 & 19 & 20 \\
\hline
\end{tabular}


7. Visuopsychic Area (Area O.A.)

\begin{tabular}{lc|c|c|c|c|c}
\hline & & Imbecile I & Imbecile II & Mongol & $\begin{array}{c}\text { Feeble- } \\
\text { minded }\end{array}$ & Normal \\
\hline L II & $\cdot$ & 74 & 70 & 74 & 80 & 80 \\
\hline \multirow{2}{*}{ L III } & $a$ & 39 & 27 & 30 & 44 & 60 \\
\cline { 2 - 7 } & $b$ & 26 & 15 & 24 & 27 & 45 \\
\hline L IV & & 126 & 74 & 86 & 88 & 150 \\
\hline L V . & $\cdot$ & 35 & 35 & 38 & 47 & 40 \\
\hline \multirow{2}{*}{ L VI } & $a$ & 36 & 33 & 29 & 30 & 55 \\
\cline { 2 - 7 } & $b$ & 18 & 13 & 11 & 16 & 12 \\
\hline
\end{tabular}

8. Visuosensory Area (Area O.C.)

\begin{tabular}{|c|c|c|c|c|c|c|}
\hline & & Imbecile I & Imbecile II & Mongol & $\begin{array}{l}\text { Feeble- } \\
\text { minded }\end{array}$ & Normal \\
\hline L III & . & 68 & 62 & 62 & 66 & 100 \\
\hline \multirow{3}{*}{ L IV } & $a$ & 99 & 106 & 85 & 90 & 150 \\
\hline & $b$ & 55 & 57 & 54 & 58 & 60 \\
\hline & $c$ & 158 & 136 & 130 & 159 & 220 \\
\hline $\mathbf{L ~ V}$ & • & 45 & 46 & 42 & 46 & 45 \\
\hline \multirow{2}{*}{ L VI } & $a$ & 103 & 78 & 69 & 85 & 140 \\
\hline & $b$ & 22 & 24 & 16 & 20 & 20 \\
\hline
\end{tabular}

From these tables it is evident that, in the majority of the areas examined, the total depth of cortex was not significantly diminished in these aments. Furthermore, the depth of the individual layers was, for the most part, equal to von Economo's normal figure, and in some instances was slightly in excess of it. Notable exceptions to the above generalization were, however, found in the agranular frontal cortex, especially in the supragranular layer of 
IMBECILE 2.

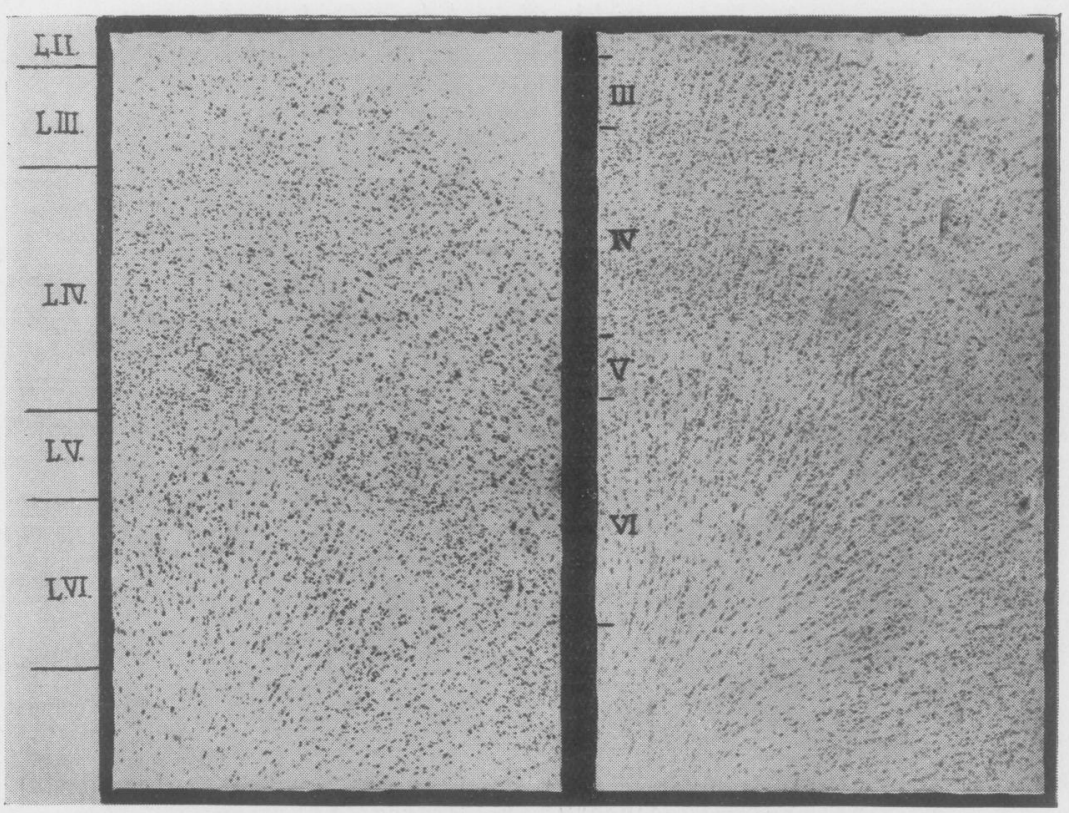

Fig. 6.-O.C. Visuosensory.

IMBECILE 1. Mongolian.

Feebleminded.

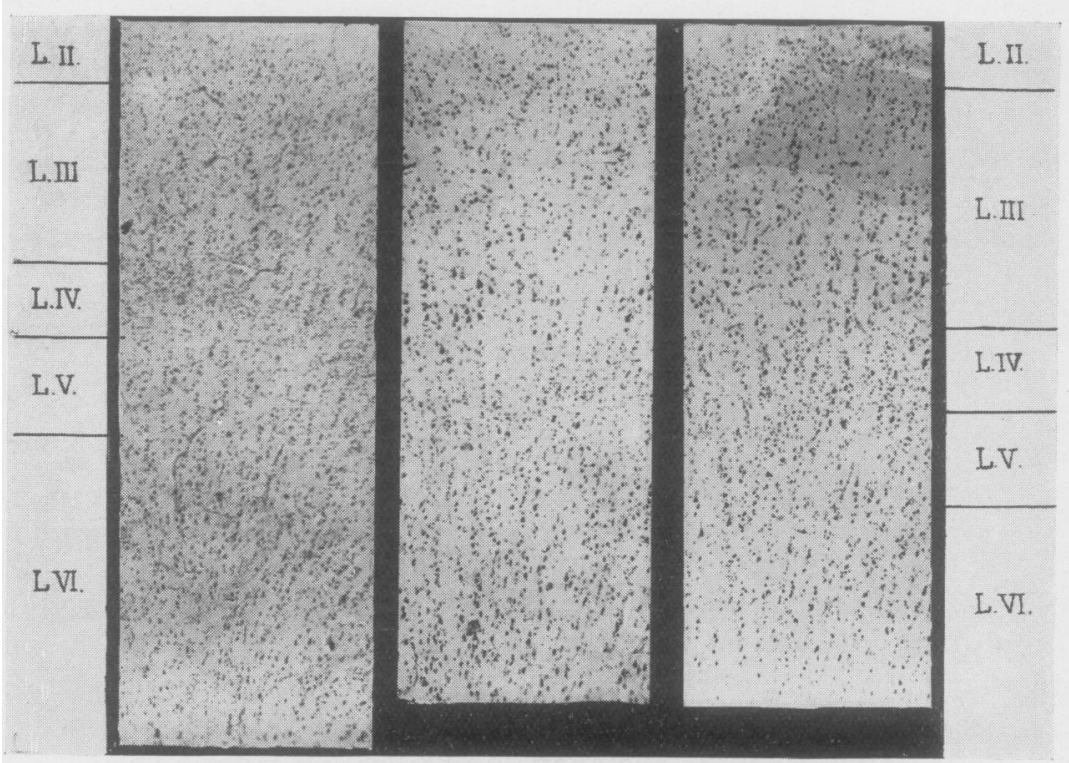

Fig. 7.-O.A. Visuopsychic. 
IMBECILE 2. Mongolian. Ferbleminded.

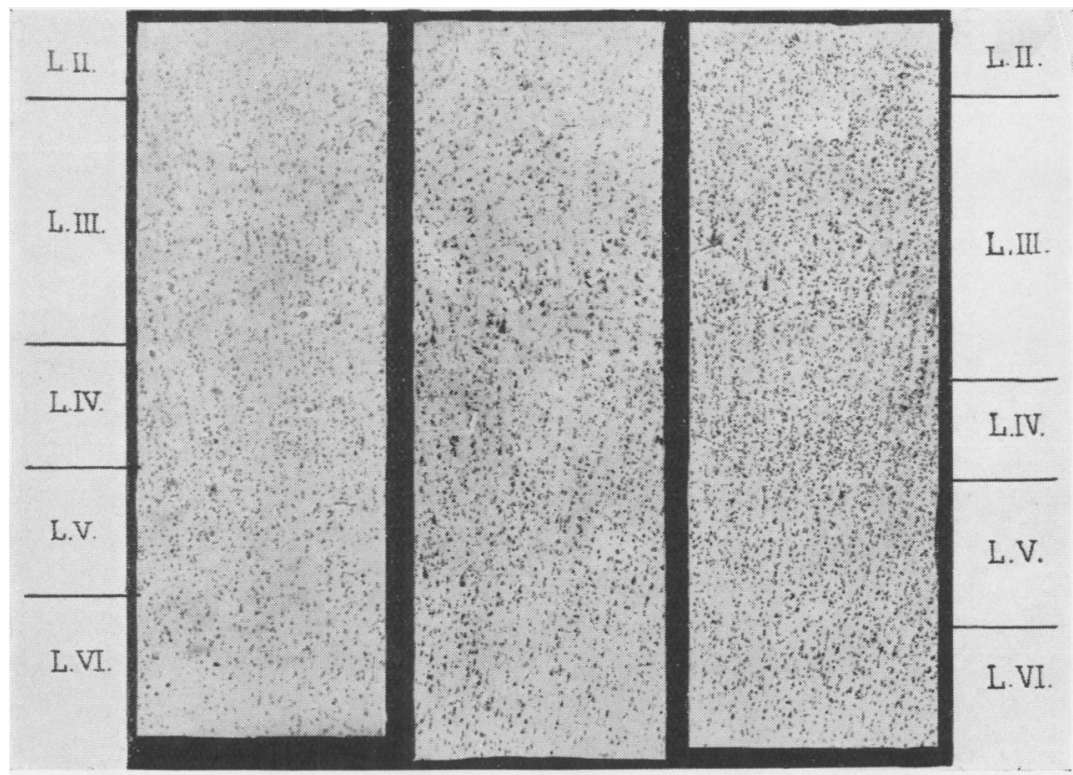

Fig. 8.-T.B. Parasensory Acoustic.

IMBECILE 1.

IMBECILE 2.

Feebleminded.

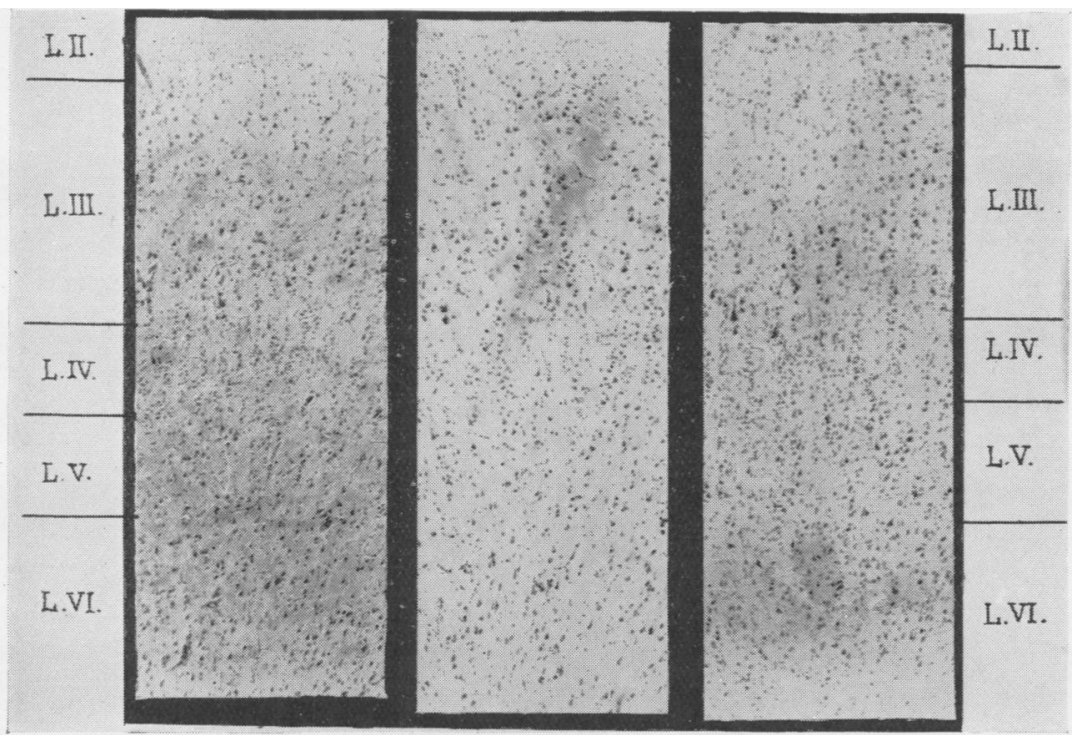

Fig. 9.-T.A. Superior Temporal. 
pyramidal cells, L III (Tables A1, A2); in the granular layer, L IV, of the superior parietal lobule (Table A4); in the supragranular layer of the parasensory acoustic area (Table A6); and in the granular layer (L IV) of the visuosensory area (Table A8). The depth of the plexiform layer (L I) was almost invariably greater in these ament brains than in the normal, but as Campbell has pointed out, the variations in depth which this layer exhibits ' have to be viewed with caution, for not only do these alter in different parts of one gyrus, but measurements are falsified by the least obliquity of the section.'

On the other hand, when the results of the cell counts (Tables B) are considered, it is clear that an entirely different state of affairs is present. In almost every instance the cell counts of the supragranular and granular elements were much below the normal. Lest it may be thought that some technical difference is responsible for this discrepancy, it must also be noticed that the cell counts of the infragranular cortex and especially of its deepest layer (L VI) approximate closely to the normal figures.

It is clear, therefore, that in order to get some idea of the neuronic efficiency of the part of the cortex examined by these methods, it is necessary to take both these factors of depth and number of cells into account. A measure of this total neuronic efficiency (so far as quantity and not quality of neurones is concerned) may be obtained by multiplying the depths of the cortical layers by the number of cells per unit these layers contain. The results of this procedure are set out in the three graphs.

In Graph BB is shown the relationship existing between the effector units of the supragranular cortex (pyramidal cells) and those of the infragranular cortex (fusiform and polymorphous cells). Graph AA shows the proportions in which all the cell layers are represented. In each case comparison with von Economo's normal is also shown. It is evident that the departure from normality is striking, and that the inferiority of these ament brains lies unmistakably in the supragranular and granular cellular development. The neuronic efficiency of the feebleminded patient with a BinetTerman mental age of $\mathbf{8 \cdot 6}$ years is also much closer to the imbecile level of the other cases than to the average normal level, but shows an appreciably better development of the parasensory acoustic area.

There are factors other than mere numbers of cells which have to be taken into account when individual differences in mentality are being discussed. One is the quality of the nerve-cells. Individual differences between the four aments are not well illustrated by a purely quantitative method, and this is in part due to the fact that in estimating the number of cells per unit in these four brains no distinction was drawn between immature neurones and neurones of good size and shape. In the cortex of the feebleminded patient the nerve-cells are generally of a better size and shape than in the imbecile cortices. In the latter, especially in the supragranular layers, instead of properly shaped pyramids, rounded or ovoid cells with scanty 


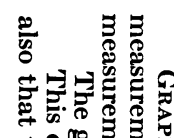

F을

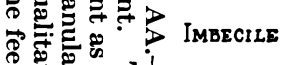

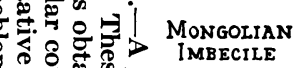

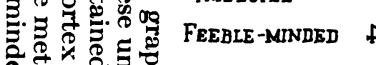

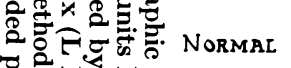

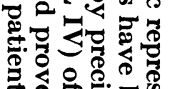

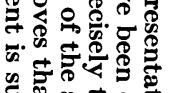

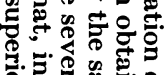

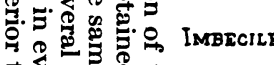

한

\%. D.

क

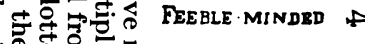

\%.

ज. 0 .

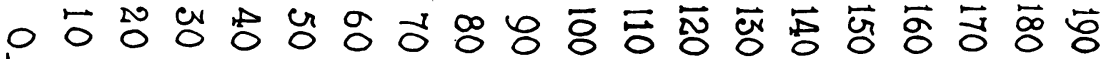

要.

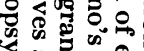

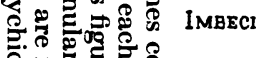

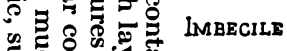

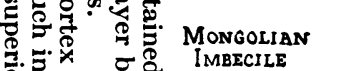

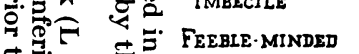

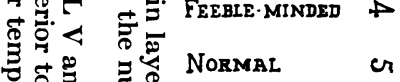

일

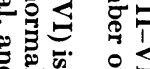

호용

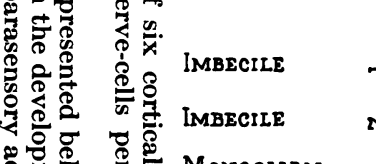

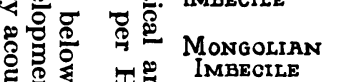

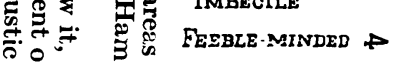

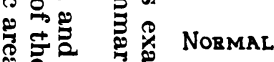

芒

胥约

ar

or
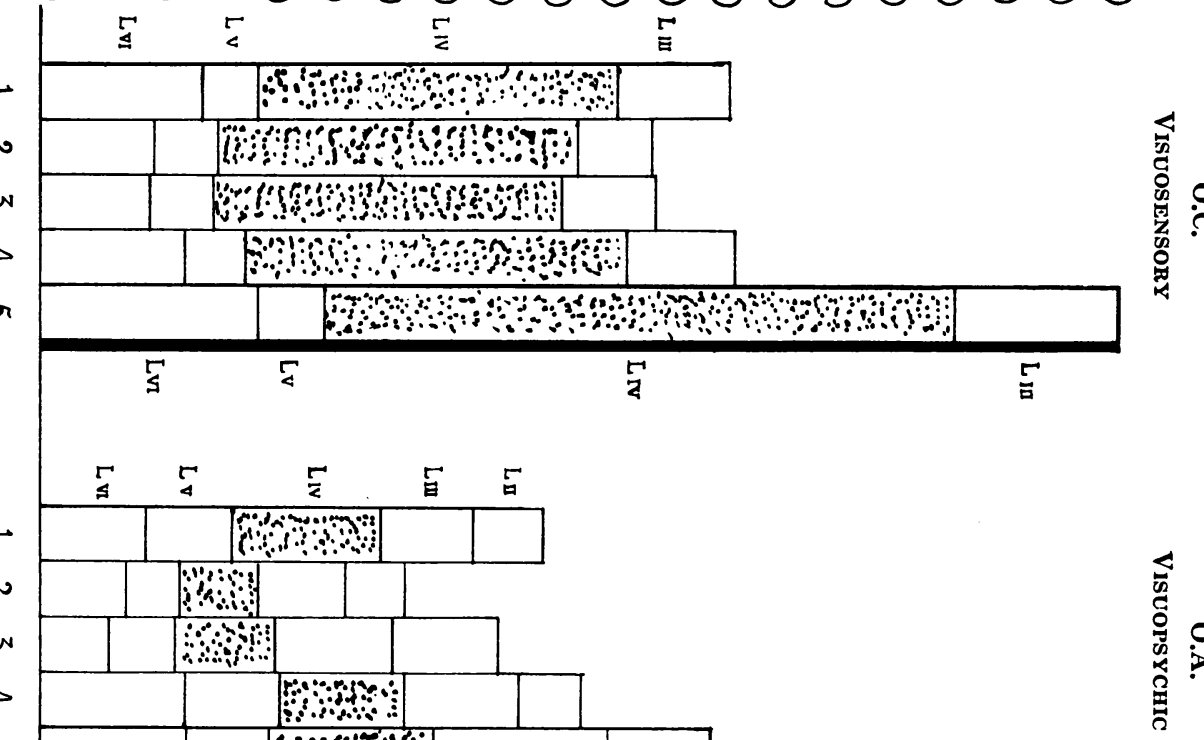

$\begin{array}{lll} & \\ & 70 & 0 \\ 0\end{array}$

Dongolian ov

范

总声 NORMAL

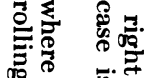

er

ing

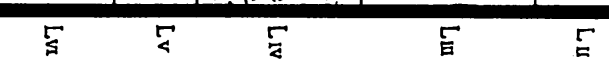

栗

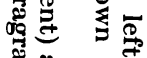

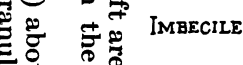

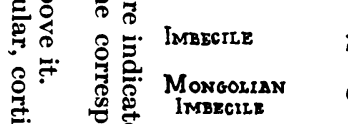

要

氙 NormaI

窇

놀용

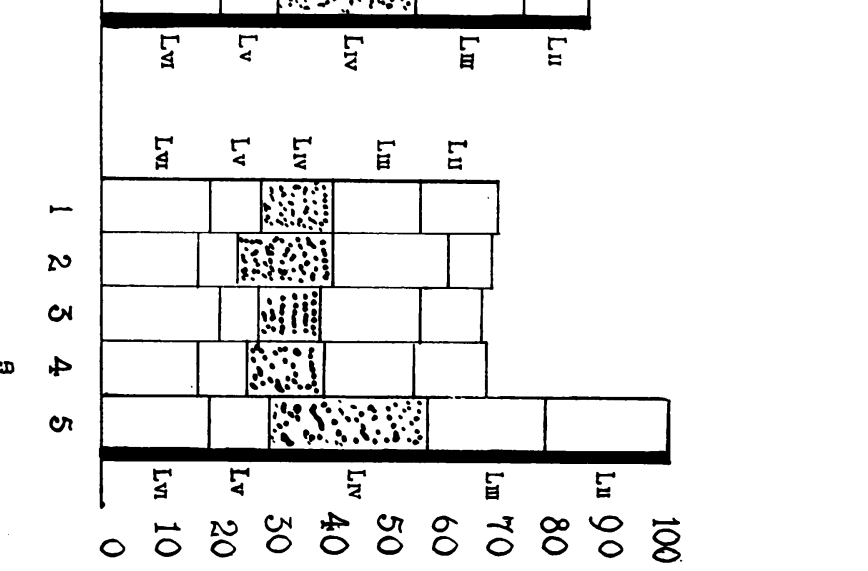

Pे

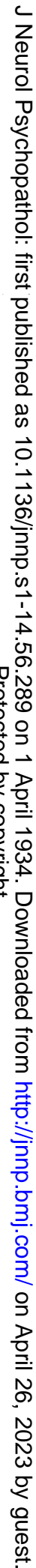

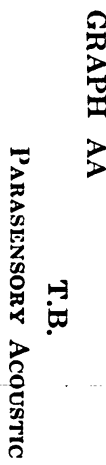

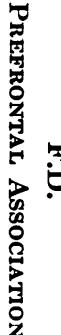

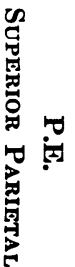

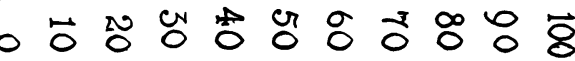




\section{GRAPH BB}

A.0.

VisUOPSYCHIC
T.B. Parasensory Acoustic
T.A. SUPERIOR TEMPORAL

50

20

F.D.

Prefrontal Association
面.B.

SUPERIo Frontal

Agragiulous

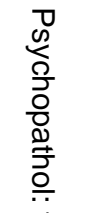

$\stackrel{\underline{0}}{3}$

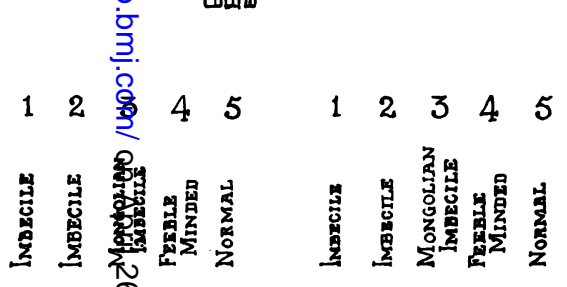

$\begin{array}{llllllllll}1 & 2 & 3 & 4 & 5 & 1 & 2 & 3 & 4 & 5\end{array}$

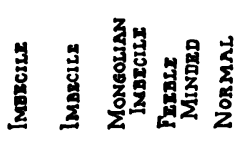

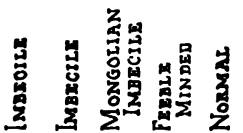
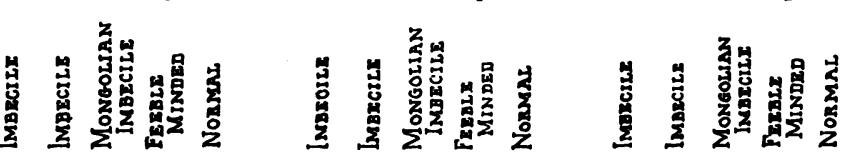

GrAPH BB.-A graphic representation of the relative proportions of the cells of the supra- and infragranth found microscopically in six cortical areas of the four defective brains. Units of measurement as in graph AA. 0 The supragranular cortex is shown in the upper half of the graph above the zero line by vertical columns with continuous lines. The infragranular corted is similarly shown below the zero line, but by columns with interrupted lines. For each area examined the standard of normality, as taken from von Economo's work, is shown on the right in solid black. The defective brains are displayed in the same order as in graph AA.

This graph illustrates the preponderance of the infragranular cortex over the supragranular, thus conforming other previous observations on the relative development of these layers. But it also brings out the further important fact that these defectives are lacking in an adequately developed supragranular cortical layer, to which is now attributed some of the higher functions of mind. In them, as thejgraph so clearly shows, the supragranular cortex is everywhere much below the normal standard in total numbers of pyramidal cells, and this is more so in some areas than others. From this microscopic evidence it is, therefore, clear that defectives suffer, not only from an undeadeveloped supragranular cortex, but from an unequally developed one as well. 


\section{GRAPH CC}

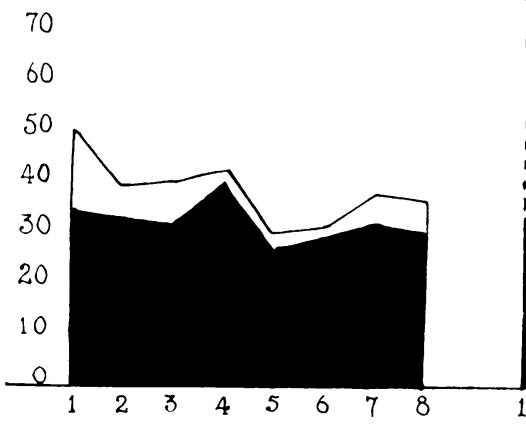

IXFRAGRANLLAR.

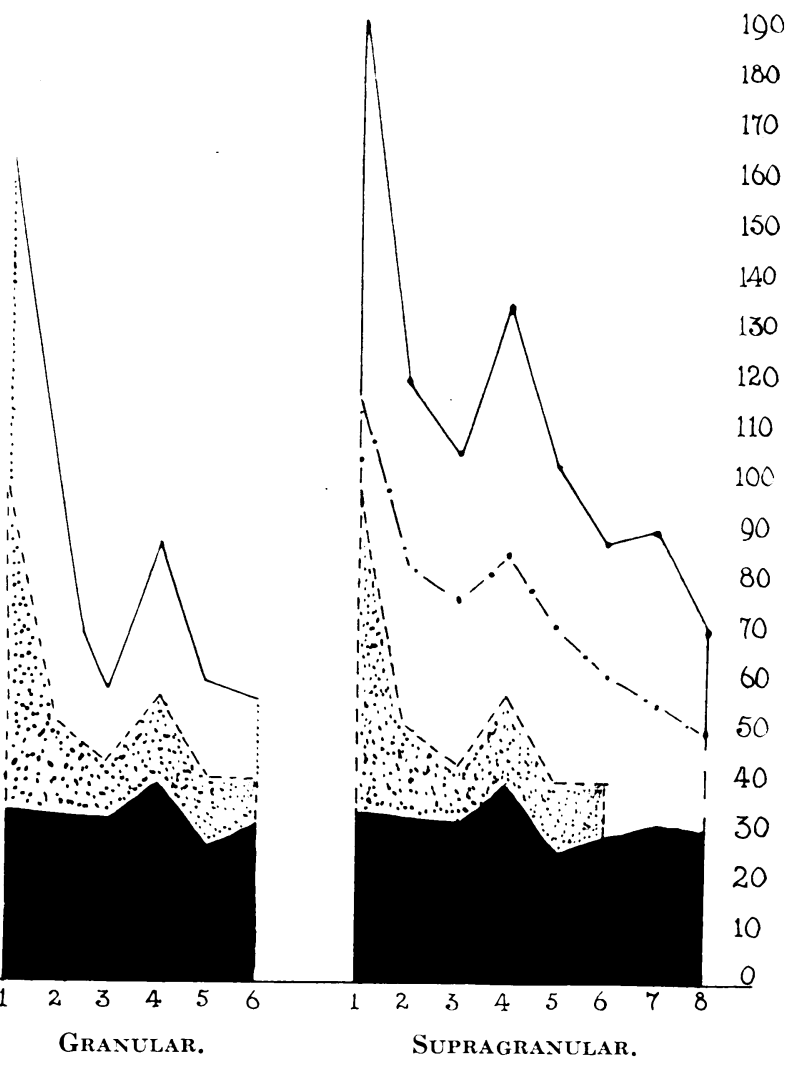

GraPh CC.- In this graph the measurements of the four defectives' cortices have been averaged in each of the eight areas examined. The units of measurement are as in graph AA. These cortical areas are numbered 1 to 8 on the base line of the three figures, and are in the same order as mentioned in the text.

In the left-hand figure the infragranular lavers of these defectives' cortices are shown in black. The normal excess above this level is indicated by an unshaded band.

In the middle figure the granular cortex of the defectives (dotted) has been added to the infragranular cortex (black). The standard for normal cortex, at this level, is shown above as an uninterrupted line.

In the right-hand figure the addition of the supragranular layer is shown as an interrupted line for the defectives, while the normal cortical level forms the upper boundary of the figure.

This graph illustrates the fact that cortical growth in the mental defective lags behind the normal, especially in the development of granular and supragranular layers. Physiologically expressed, these structural facts mean that the defective suffers from an inferior receptivity of stimuli and an inadequate power of integration and inhibition. 
IMBECILE 1.

IMBECILE 2.

Feebleminded.

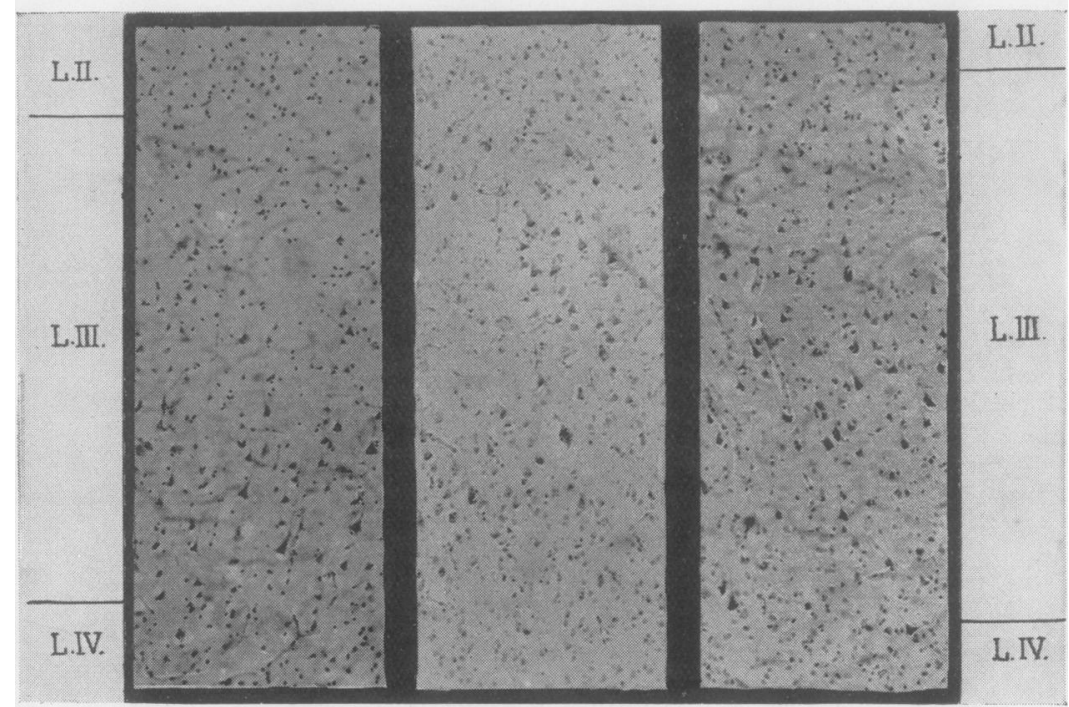

Fig. 10.-F.D. Frontal Association.

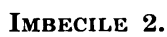

Mongolian.

Feebleminded.

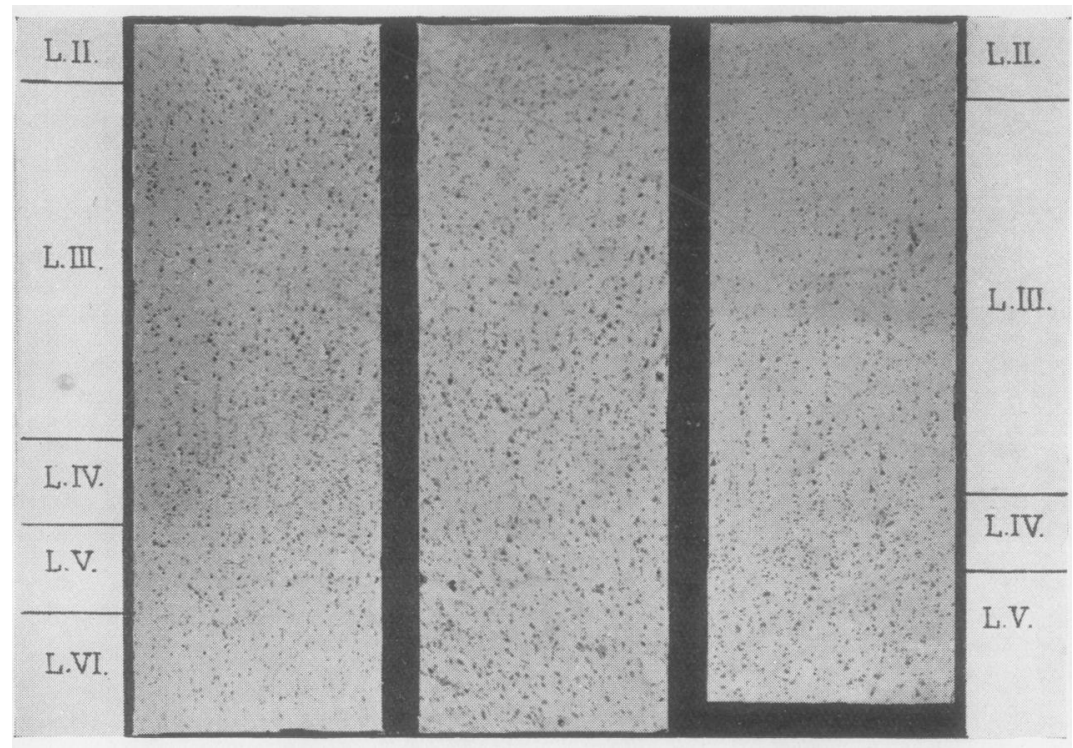

Fig. 11.-P.E. Superior Parietal. 
cytoplasm and large pale nuclei are of frequent occurrence (see fig. 13b). A further peculiarity of such cells was their affinity for silver salts (see fig. 13c). These abnormalities in morphology and staining reactions are characteristic of the neuroblast, and it would thus appear probable that these illformed pyramidal cells are immature neurones.

Another factor to be considered when cortical structure is to be correlated with psychic activity is the general arrangement of the neurones. The microphotographs show that, with the exception of the frontal association area (fig. 10), the general architectural pattern of the cortex of the feebleminded woman is superior to that of the other cases. In her cortex not only is the horizontal lamination more clearly defined, but the vertical arrangement of the cells is more regular, thus indicating a greater wealth of intercellular fibres. Evidence for the latter conclusion is given by sections prepared by Bolton's iron alum method, which show that the myelinated fibres in these ament cortices are very inferior in numbers to those in a normal brain stained by the same method. This also shows that the radial bundles in the feebleminded cortex are larger than those in the imbecile. The lamination of the lower grade cortices was indeed often so confused that careful search had to be made along the crown of the section to find a part of the layer in a sufficiently demarcated state to admit of accurate measurement. Since mental life is the expression of the complexity and orderly development of cortical neuronic arcs, this factor of neuronic arrangement is of great importance.

When these factors of total numbers, quality, and arrangement of nervecells are reviewed in conjunction with the preponderance of the infragranular cortex present in all these cases, it is clear that the departure of these aments from the normal standards of mentality is explicable in terms of cortical structure. Furthermore, the two years' advantage in mental age possessed by the feebleminded patient over the imbecile is reflected both in the generally better cellular and architectural quality of the cortical areas examined as also in the superior development of the auditory zones.

\section{SOME OTHER GORTIGAL ABNORMALITIES DISGOVERED DURING THE GOURSE OF THE INVESTIGATION}

Amongst these were the following :

Abnormalities in the Frontal Association Areas.-A feature of these four brains is the presence of very poorly developed frontal association areas. The poverty of the two granular layers ( $L$ II and L IV) gives the sections the appearance of an intermediate (F.C.) type of cortex-namely, of that found in normal brains as a narrow strip lying between the agranular precentral areas and the well developed sesquilaminated frontal association area (F.D.).

In the frontal agranular areas (F.A. and F.B.) these four brains all show a considerable diminution in depth of, and number of cells in, the pyramidal cell layer III. In the Mongolian imbecile defective 'pyramidization' (von 


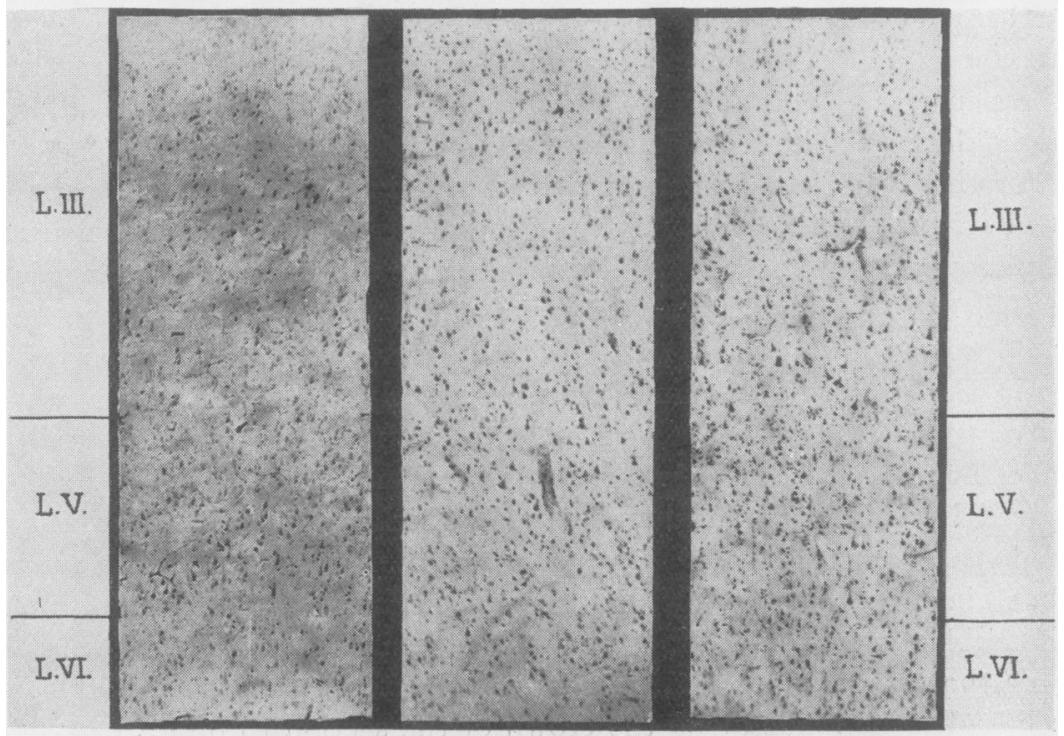

Fig. 12.-F.B. Frontal Agranular.

Mongolian.

IMBECILE 1.
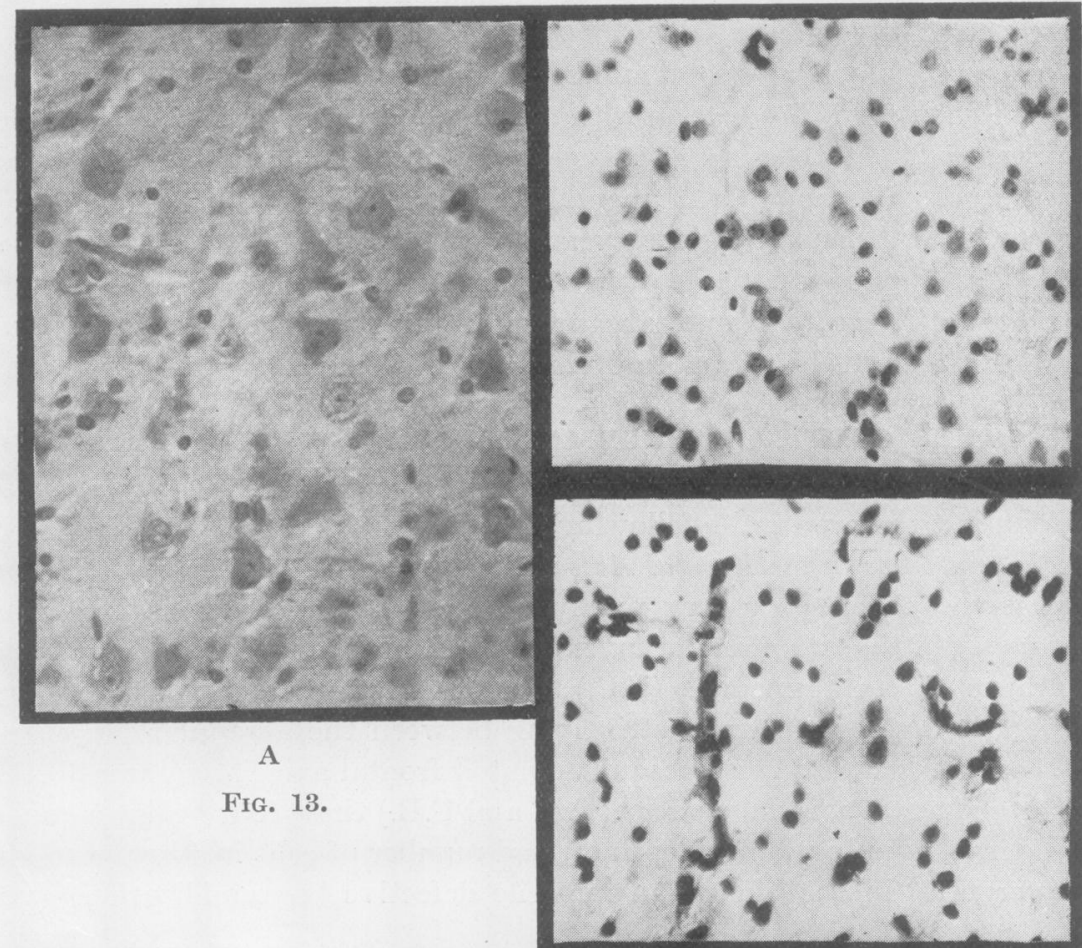

Frg. 13. 
IMBECILE 2. Mongolian. FEebleminded.

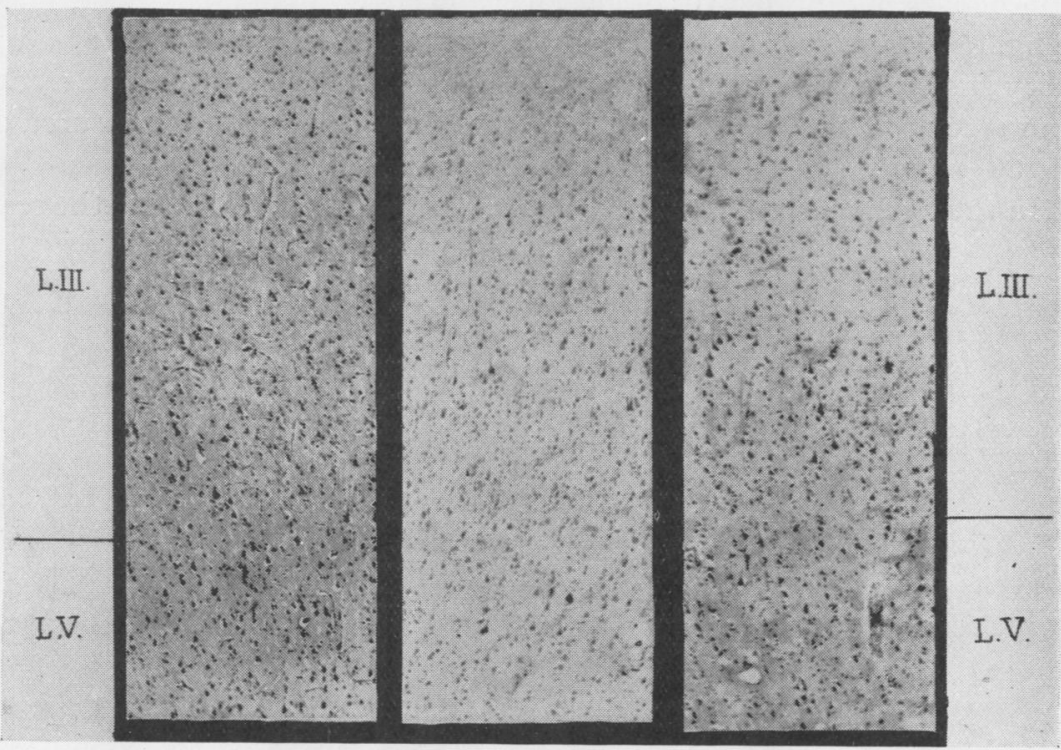

Fig. 14.-F.A. Rolandic Agranular Motor Area.

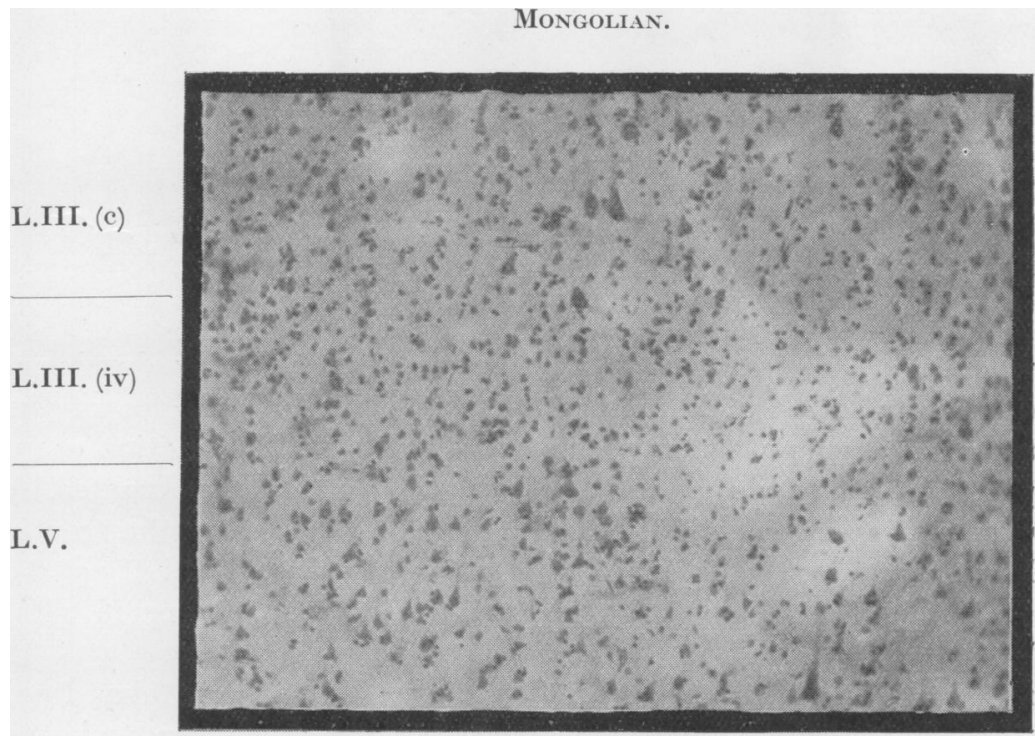

Fig. 15.-F.A. Defective Pyramidization. 
Economo) of the cells in the lower part of layer III has occurred. That is to say, instead of a normal layer III (iv) consisting of medium pyramidal cells $20 / 10 \mu$ in size, a diffuse layer of granular and small pyramidal cells is present (see fig. 15). The Betz cells of the Rolandic motor area are smaller and not, as they should be in normal circumstances, an obvious feature of the sections. In our second imbecile the largest Betz cell seen in one section measured only $68^{\circ} \times 39 \mu$, and in the feebleminded woman only $40 \times 20 \mu$.

In the Mongol (see fig. 13A) the frontal association area is also the seat of

Feebleminded.

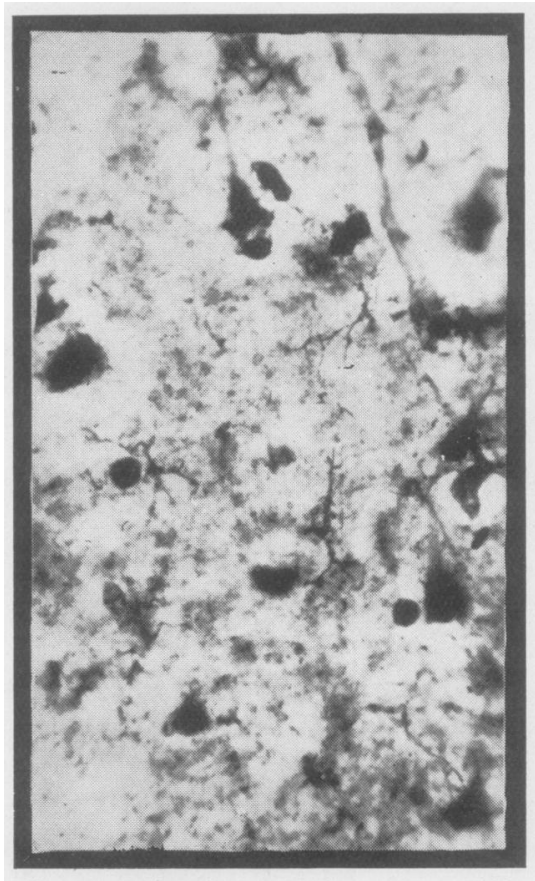

Fig. 16.-Microglia.

early degenerative changes, thus suggesting that these poorly developed pyramidal cells exhibited a diminished durability in the presence of the agonal stresses of toxæmia and raised temperature. This association of an undeveloped frontal lobe with an impaired mentality is also corroborated by Bolton, who, in his Henderson Trust Lectures (1933), says that the frontal lobe is ' the portion whose evolution renders possible the actual activity of the human mind ...' and 'constitutes in fact the essential factor in vital activity.'

Abnormalities in the Parietal Association Areas.-In sections taken from the posterior end of the superior parietal lobule (area P.E.) the second imbecile shows an additional topographical abnormality. This part of the cortex had 


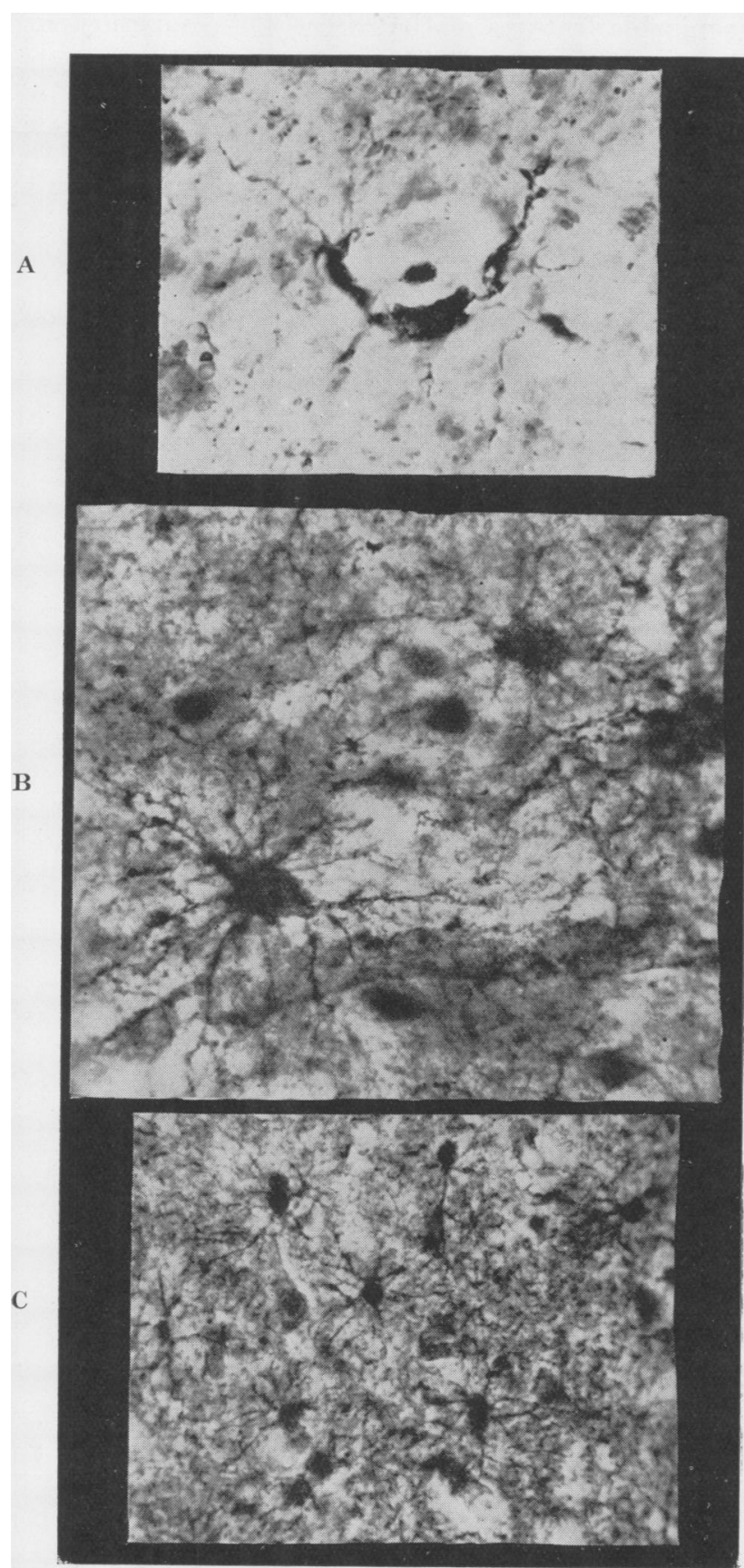

FIG. 17.-Neuroglia. 
the easily recognizable features of that area of the superior parietal lobule which normally should lie immediately posterior to the somæsthetic sensory area (P.B.). These features consist essentially in the presence of giant cells in L III. But in this imbecile's brain sections taken from the anterior part of the parietal lobule show the ordinary superior parietal formation with no

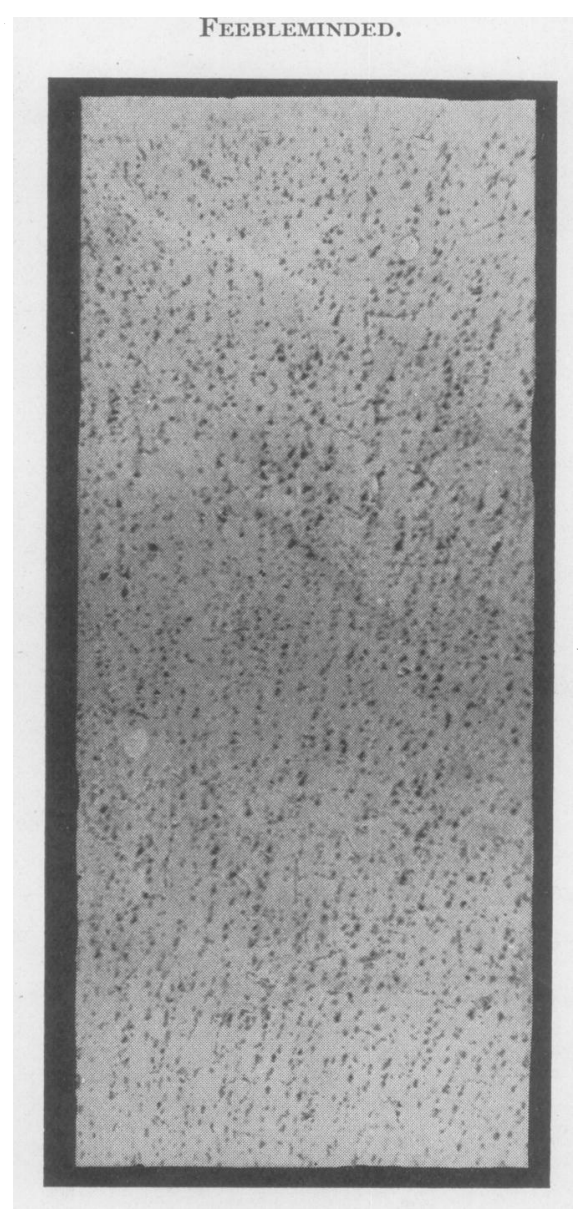

Fig. 18.--Inferior Parietal.*

giant cells in L III. This accidental finding suggests that a more elaborate mapping of the cortical areas in mental defectives would bring to light many minor aberrations of localization.

Abnormalities in the Temporal Acoustic Areas.-Another indication supporting the above suggestion that the abnormalities in the positions of

* This area, taken from the angular gyrus, was one of the most normal found. The depth and cell jeounts were:-L I 0.26 ; L II 0.26 (76); L III 0.82 (29); L IV 0.22 (102); L V 0.53\}(20); L VI 0.82 (15). Normal : L I 0.22; L II 0.20 (95); L III 0.80 (25); L IV 0.35 (100+); L V 0.55 (18); L VI 1.2. (15). 
recognized cortical fields may be of frequent occurrence in mental defectives is furnished by the second imbecile. In this case, four different blocks of cortex were removed from the gyri of Heschl of the left side in an attempt to locate the auditosensory area. Microscopic examination, however, revealed only cortical areas of parasensory type (T.B. or T.D.), thus showing that the auditosensory area had either developed in an abnormal situation or must have been very seriously reduced in extent.

Abnormalities in the Occipital Visual Areas.-In the same imbecile (case 2) the calcarine fissure was abnormally short. As measured from its junction with the parietooccipital fissure, it was only $0.5 \mathrm{~cm}$. in length. It then divided into two terminal branches, the longer of which continued the direction of the parent stem towards the occipital pole for a distance of 0.9 $\mathrm{cm}$., the shorter proceeding upwards for a distance of $0.3 \mathrm{~cm}$. Thus the whole length of the fissure did not reach halfway along the medial surface of the occipital lobe, the total length of the latter being $3 \cdot 2 \mathrm{~cm}$. This anatomically abnormal short calcarine fissure is suggestive, of course, of a consequent diminution in the numbers of receptive granular visuosensory neurones. Microscopic examination of the area in question revealed no compensatory excess in either numbers of neurones or depth of cortex. It was, in fact, one of the worst of the series in both respects.

The poverty of a primary receptive sense zone should be reflected in the secondary, for development of the latter depends on correct stimulation by the former. It is to be expected that in this imbecile the visuopsychic area should reveal microscopic evidence of this lack of stimulation, and indeed it did so and was easily the most poorly developed of any of the four cases. Thus in the visuopsychic area of this imbecile L IV was wavy in appearance and varied considerably in total depth. Even the infragranular cortex shared in the general agenesia. $\mathrm{L}$ V was extremely poorly defined and L VI at the crown of the section showed many stellate instead of the fusiform cells which should be found in this situation.

The Agenesia of the Granular Layers.-Since these four brains all exhibit a measurable reduction in numbers of granular (receptive) neurones (L II and L IV) and do so in all parts of the cortex where these layers are normally present, there is every reason for supposing that this factor must, in its turn, have been responsible in part for the general cortical agenesia of pyramidal and other nongranular cells found in these brains. Ariëns Kappers and other authors hold that the Golgi Type II neurones of the cortical granular layer are strongly ' receptive and correlative' in function, and that they transmit, sooner or later, the nervous impulses which they modify to the effector elements. It thus follows that if the effector cells receive only an impaired stream of impulses, their development will tend to remain at a low level. Thus the lack of numbers of these effector cells may be attributed to a primary agenesia, and their poor quality to lack of stimulation. Clinical examination showed that these patients were not defectives from 'deprivation of the 
senses' in the ordinary sense of the term, but were so because a maldeveloped cerebral cortex is incapable of ' using' the stimuli faithfully transmitted to it from the environment.

\section{GONCLUSIONS}

From the microscopic examination described in the text, it may be concluded that :

1. There is a significant reduction in the numbers of supragranular and granular neurones, though the total depth of cortex at the crowns of the gyri is not appreciably diminished except in the agranular frontal cortex.

2. These cortices are of inferior neuronic construction. The brain cells are irregularly arranged, tend to be small in size and are often of abnormal shape. Further, topographical variations may be present in low grade cortices, as has been noted in at least one of these imbeciles.

3. The cortex of the feebleminded case mainly differs from the imbecile in the more normal arrangement and shape of its cells. It is thus not improbable that the difference in cortical structure between high and low grade aments is one of degree.

\section{SOME GLINICAL AND GENERAL GONSIDERATIONS}

Both macroscopically and microscopically the relationship of these brains to the relative mental states of the patients is so obvious as to require no further demonstration. Their undeveloped condition sufficiently accounts, without any superadded psychological or other theoretical explanation, for the admitted legal mental deficiency during life. The imbeciles, for example, could not write, read, count, or attend to their own requirements, notwithstanding that much time had been devoted to their socalled ' educational' and manual training.

As the cerebral irregularities displayed by these cases are prenatal in origin, and incapable of structural alteration by postnatal treatment, it would appear to be futile to expect 'cures,' for no form of educational, psychological, or occupational therapy can supply brain cells where nature has denied them. More stable habits can, of course, be established partly as the result of a natural chronological growth and partly by persistent and constant training, which in many of these aments-including some of the lower grade feebleminded defectives-is of little more value than a filling in of time between eating and sleeping.

The discovery in many defectives of a clinical syndrome, or of some condition simulating one, is sometimes assumed to be evidence warranting a diagnosis of secondary or exogenous amentia. Organic nervous disease can be, and often is, engrafted on to a preexisting endogenous amentia, and the latter condition naturally tends to increase the incidence of nervous degenerations amongst defectives, in whom they are, indeed, very common. Thus the first imbecile of the present series displayed during life the clinical 
picture of extrapyramidal paralysis of Parkinsonian type, and a characteristic paucity of nerve-cells was discovered later in the substantia nigra. A moderate degree of gliosis and an increased number of bloodvessels indicated a chronic degenerative process. Yet the grossly abnormal fissuring of the brain and the microscopic deficiency of cortical neurones are those of the primary ament.

Any considerable reduction in the number of cortical neurones is attended by a corresponding reduction in the numbers of the medullated axons of the associational, commissural, and projection systems. The corticipetal (receptor) and corticifugal (effector) axons of the last named system pass between the cerebral cortex and practically all other parts of the nervous system. The diminished size of the corpus callosum, and more particularly the underdevelopment of the post- and precentral convolutions, as well as that of the Betz and other pyramidal cells, suggest the consequential fact that, in these cases, other parts of the central nervous system must have shared in the lack of development so clearly indicated by the cerebral cortex. Such underdeveloped nervous systems necessarily function so imperfectly as to give rise to aberrant neurological phenomena which, whilst occasionally simulating the syndromes of disease, for which they are readily mistakable, are in reality of developmental, not pathological, origin. In a previously normal individual precisely the same reduced level of neuronic efficiency may be reached as a result of genuine disease processes. Of the many lessons which the defective brain and nervous system of the ament have to teach, one is, apparently, that syndromes of neurological disorders closely resembling one another may, in reality, have two quite different origins, the one developmental, the other pathological-facts which have a possible bearing on both diagnosis and treatment.

That the ament, with his considerably reduced expectation of life and his consequent much earlier senility - that is, a physiological degeneration of nerve and other cells-frequently combines both causes within his own person, occasions no surprise. It is, indeed, not improbable that these facts also apply, in lesser degree, to patients other than defectives of inferior neuronic development who develop phenomena resembling neurological syndromes more usually caused by organic disease. If so, this would be in accordance with the clinical conception of abiotrophy applied to many of the familial degenerative syndromes of the central nervous system and defined by Karsner as follows : 'this socalled nervous abiotrophy seems to occur in cases in which, owing to hereditary or other inherent defect, certain localized regions are unusually susceptible to deterioration.'

All the cells of the human body-somatic, reproductive, and nervousresult from repeated subdivision of a fertilized ovum. In amentia there is a reduction of the numbers of nerve and, presumably, other cells. Primary mental deficiency is thus a genetic manifestation of the inability of a fertilized human ovum of usually impaired stock to undergo a correct cellular division 
and multiplication. Hence the physical basis of so many mental and nervous disorders and the potent influence of heredity in their production and transmission.

\section{APPENDIX}

1. Note on the Neuroglia and Microglia.-The cortices of one of the two imbeciles, the Mongolian imbecile and the feebleminded woman, were examined by Cajal's gold sublimate method and Rydberg's silver-diamino-carbonate and combined gold-silver methods for the study of the neuroglial and microglial elements. The distribution of the protoplasmic astrocytes (see fig. 17c) suggests that the thickness of these cortices, which is surprisingly normal when compared with the neuronal poverty they display, is due to the ramifications of glial processes and to an increased number of the glial cells. These fill out the spaces between the scattered and numerically diminished neurones. The microglial cells were generally numerous, of the somewhat swollen (see fig. 17a) and occasionally present as long bipolar forms.

2. Technique.-Fixation.-Ten per cent. formol saline solution was injected into the cisterna magna and through the orbits into the interior of the skull immediately after death. After removal, the brain was suspended in the same fixative and on the third day small incisions were made to allow the fluid freer access to the ventricles.

Methods used in Measurements and Cell Counts.-The blocks removed from the cortical areas to be examined have to be cut at right angles to the surface of the brain and to the direction of the gyrus. Two factors tending to flatter the defective now become operative. The first is that the macroscopically better formed gyri are selected, since they are easier to cut ; the second is that any obliquity of cutting in the process of removing the block of tissue will increase the depth of the layers to be measured.

Sections were cut on a freezing microtome at $25 \mu$ and stained by 1 per cent. toluidin blue. It was found best to fix each section to an albuminized slide owing to the tendency of the section to shrink in the xylol stage of the staining process. The depth of the cortical layers at the crown of the section was measured by means of an eyepiece micrometer $(\times 10)$ using a Leitz No. 3 objective. For the cell counts an Ehrlich eyepiece was used in conjunction with a No. 6 objective, the average of at least twenty contiguous fields being taken. This result was then converted into the Hammarberg unit-namely, the number of cells present in $0 \cdot 1$ cubic millimetres.

\section{EXPLANATION OF THE ILLUSTRATIONS}

Fig. 1.-Photograph of a normal brain for comparison with those of the four defectives. Figs. 2-5.-Photographs of the four defective brains described in the text.

Figs. 6-12 and Figs. 14 and 18.-Microphotographs of different cortical areas of the defective brains showing the cellular variations of structure. Toluidin blue. $\quad \times 48$.

Fig. 13.- $(a)$ Cortical neurones of the frontal association area of the Mongol, showing early degenerative changes. Toluidin blue. $\times \mathbf{3 6 0}$.

(b) Lamina II of the visuopsychic area of imbecile no. 1, showing numerous rounded immature neurones instead of fine pyramidal cells. Toluidin blue. $\times \mathbf{3 6 0}$.

$(c)$ As in (b), but stained by Rydberg's silver-diamino-carbonate method. $\times \mathbf{3 6 0}$.

Fig. 15. - Section of the Rolandic motor area (normally agranulous), showing the presence in the Mongol of an abnormal granular layer. Toluidin blue. $\times \mathbf{8 0}$.

Frg. 16.-Microglia in the Rolandic motor cortex of the feebleminded woman. Combined gold-silver method. $\times \mathbf{3 6 0}$.

Fig. 17.- (a) As in fig. 16. $\times 800$.

(b) Protoplasmic astrocytes in L III of the Rolandic motor cortex of the feebleminded woman. Cajal's gold sublimate method. $\times \mathbf{8 0 0}$.

(c) Protoplasmic astrocytes in L III of the Rolandic motor cortex of the Mongol. $\times 360$. 